\title{
IG \\ p \\ NORK \\ Work Incentives of Medicaid Beneficiaries and the Role of Asset Testing
}

Svetlana Pashchenko

Ponpoje Porapakkarm

Working Paper

2016-016

$07 / 2016$

HUMAN CAPITAL AND

ECONOMIC OPPORTUNITY

GLOBAL WORKING GROUP
The University of Chicago 1126 E. 59th Street Box 107 Chicago IL 60637 


\title{
Work Incentives of Medicaid Beneficiaries and The Role of Asset Testing *
}

\author{
Svetlana Pashchenko ${ }^{\dagger}$ \\ University of Georgia
}

\author{
Ponpoje Porapakkarm ${ }^{\ddagger}$ \\ National Graduate Institute \\ for Policy Studies (GRIPS)
}

July 7,2016

\begin{abstract}
Should asset testing be used in means-tested programs? These programs target low-income people, but low income can result not only from low productivity but also from low labor supply. We aim to show that in the asymmetric information environment, there is a positive role for asset testing. We focus on Medicaid, one of the largest means-tested programs in the US, and we ask two questions: 1) Does Medicaid distort work incentives? 2) Can asset testing improve the insurance-incentives trade-off of Medicaid? Our tool is a general equilibrium model with heterogeneous agents that matches many important features of the data. We find that $23 \%$ of Medicaid enrollees do not work in order to be eligible. These distortions are costly: if individuals' productivity was observable and could be used to determine Medicaid eligibility, this results in substantial ex-ante welfare gains. When productivity is unobservable, asset testing is effective in eliminating labor supply distortions, but to minimize saving distortions, asset limits should be different for workers and non-workers. This work-dependent asset testing can produce welfare gains close to the case of observable productivity. JEL Codes: D52, D91, E21, H53, I13, I18
\end{abstract}

Keywords: means-tested programs, health insurance, Medicaid, asset testing, general equilibrium, life-cycle models

${ }^{*}$ We thank Orazio Attanasio, Gadi Barlevy, Mariacristina De Nardi, Eric French, Mikhail Golosov, Gary Hansen, Roozbeh Hosseini, Robert Kaestner, Greg Kaplan, Karen Kopecky, Matthias Kredler, Paul Klein, Vincenzo Quadrini, Victor Rios-Rull, Yongseok Shin, Kjetil Storesletten, Ija Trapeznikova, Gianluca Violante, Tomoaki Yamada, Pierre Yared, Eric Young, two anonymous referees, and all seminar participants at the Chinese University of Hong Kong, the Federal Reserve Bank of Chicago, GRIPS, ETH Risk Center Workshop, IFS, University of Tokyo, EFACR group in NBER Summer Institute, Mannheim Macro workshop, Midwest Macro meeting in Urbana, NASM in Minneapolis, Nordic Macro Workshop in Smögen, SED meeting in Seoul, Pacific Rim Conference in Tokyo, Vienna Macro Workshop, and Greater Stockholm Macro Group for their comments and suggestions. This work is supported by JSPS KAKENHI Grant Number 15K03505 and GRIPS' Research Project Grant. All errors are our own.

†Email: svetlana@uga.edu

†Email: p-porapakkarm@grips.ac.jp 


\section{Introduction}

Should asset testing be used in means-tested programs? The total federal spending on ten major means-tested programs and tax credits increased more than tenfold over the last four decades, reaching $\$ 588$ billion or $4 \%$ of GDP in 2012 (CBO, 2013). Yet, little consensus exists on certain aspects of these programs' design, in particular, asset testing. The overall trend over the last decade was toward abandoning the asset testing policy, but the debate concerning its use continues. As a recent example, asset testing for the food stamps program was one of the central issues in the debate over the 2014 Farm Bill. ${ }^{1}$

In this paper, we aim to show that there is a positive role for asset testing in the asymmetric information environment. Means-tested programs target low-income people by restricting its enrollees to earn less than a certain limit. This requirement prevents high-income workers from obtaining public transfers, but it cannot guarantee that nonworkers with potential income above the income limit do not enroll. Because earning ability is unobservable, once an individual with high labor income stops working, he is indistinguishable from those whose potential labor income is low. In this environment, asset testing can be used as an additional tool to improve the ability of means-tested programs to target the most disadvantaged people.

We focus on Medicaid, which is one of the largest means-tested programs in the US and also an important source of health insurance coverage for the non-elderly poor. The fraction of workers among Medicaid enrollees is substantially lower than this fraction among the rest of the population; on average, non-disabled Medicaid beneficiaries are twice less likely to work than people with private insurance or the uninsured. ${ }^{2}$ In this paper, we ask two questions: 1) Does Medicaid significantly distort work incentives? 2) Can asset testing improve the insurance-incentives trade-off of Medicaid without changing the amount of redistribution in the economy? More specifically, our goal is to quantify the distorting effects of Medicaid on work incentives, assess its welfare implications, and illustrate how asset testing can mitigate these distortions. Our important contribution is to show that work-dependent asset testing can eliminate labor supply distortions without creating significant distortions on savings.

Our approach is a quantitative general equilibrium model with the following key features. First, we allow for heterogeneity of individuals along the dimensions of health, productivity, and medical expense shocks. This allows us to capture the insurance role of Medicaid for people with bad health, large medical shocks and/or low productivity.

\footnotetext{
${ }^{1}$ The 2014 Farm Bill reauthorized the Supplemental Nutrition Assistance Program (SNAP), formerly known as the food stamps program. The House version of the Bill proposed to repeal the broad-based categorical eligibility, which allows states to bypass asset testing when determining SNAP eligibility. In contrast, the Senate version of the bill made no changes to the broad-based categorical eligibility

${ }^{2}$ Own calculations from Medical Expenditure Panel Survey dataset; see Section 5 for details.
} 
Second, we let health affect productivity and opportunity to access employer-based insurance, which allows us to model the selection of people with low attachment to the labor force into Medicaid. ${ }^{3}$ Third, people in our model have several options to insure against medical shocks: self-insurance, public health insurance, and private health insurance (employer-based and individual). However, private health insurance is not easily accessible for two reasons. First, employer-based insurance is only available for the subset of the population working at firms that offer this type of insurance. Second, the individual market is risk-rated, meaning that unhealthy people face high premiums. People who want to obtain public insurance have to meet an income test and an asset test. Because labor income is endogenous, Medicaid beneficiaries in our model include those who have low earning ability and those who have relatively high earning ability but choose not to work to be eligible. Fourth, we introduce disability shock into the model to be able to separate disabled and non-disabled individuals in our analysis, i.e., to distinguish between people who can work (and whose labor supply decisions can be distorted by the Medicaid eligibility rules) and those who cannot (because they are disabled). Finally, we model other non-Medicaid government means-tested programs to represent adequately the public safety net existing in the economy.

We calibrate the model using the Medical Expenditure Panel Survey (MEPS) dataset. More specifically, we require the model to reproduce the following key patterns of the data separately for each health group: i) the life-cycle profiles of health insurance takeup, ii) the life-cycle profiles of employment, iii) the average labor income profiles for all workers and for workers without employer-sponsored health insurance (ESHI). An essential feature of our calibration is that we use our model to estimate the potential labor income and chances to access ESHI of individuals whom we do not observe working in the data. This is important for understanding how Medicaid affects labor supply decisions because a large fraction of Medicaid beneficiaries do not work.

Our findings are as follows. First, around $23 \%$ of non-disabled Medicaid enrollees would choose to work if they were able to keep their access to public insurance. The majority of this group is unhealthy and has higher medical costs and higher assets than other Medicaid enrollees.

Second, these distortions are important in welfare terms. If we remove the asymmetric information problem, i.e., link Medicaid eligibility to (unobservable) exogenous productivity as opposed to (observable) endogenous labor income while keeping the budget of public transfer programs constant, this will result in ex-ante welfare gains equivalent to $1.17 \%$ of annual consumption.

\footnotetext{
${ }^{3}$ In the data, $43.2 \%$ of non-disabled Medicaid beneficiaries are unhealthy, whereas the unhealthy among the privately insured and the uninsured account for only $13 \%$ and $24.5 \%$, respectively. In addition, unhealthy people are less likely to be covered by employer-based health insurance. Only $48 \%$ of the unhealthy are covered by employer-based health insurance compared with $67 \%$ among the healthy.
} 
Third, we study how asset testing can be used to reduce the labor supply distortions when productivity is unobservable. We show that strict asset testing (with the asset limit equal to $\$ 2,000$ ) can almost completely eliminate the moral hazard problem; the percentage of Medicaid beneficiaries who stop working to obtain Medicaid decreases from $23 \%$ to $1 \%$. However, this reduction in labor supply distortions comes at the cost of large saving distortions that substantially decrease the welfare gains of this policy. In contrast, if asset limits are allowed to be different for workers and non-workers, asset testing can achieve an outcome that is very close to the "ideal" case of observable productivity. This happens because strict asset testing of non-workers prevents highly productive individuals from using the following strategy: stop working, claim Medicaid and then use their accumulated assets to smooth consumption. In contrast, loosening asset limits on working beneficiaries relieves saving distortions for individuals who do not "game" Medicaid rules by lowering their labor supply. ${ }^{4}$

The results of our policy analysis can reconcile the opposite findings from three recent empirical studies that examine the effect of public insurance on labor supply using changes in the Medicaid expansion programs in three states. Garthwaite et al. (2014) and Dague et al. (2013) find that Medicaid has a large effect on labor supply in Tennessee and Wisconsin, respectively, whereas Baicker et al. (2014) conclude the opposite for the case of Oregon. Importantly, the Medicaid expansion programs in Tennessee and Wisconsin had no asset testing, while the program in Oregon imposed a strict asset limit of $\$ 2,000$. In light of our findings, the different intensity of the moral hazard problem in these three cases can be attributed to the difference in the asset testing policies.

The paper is organized as follows. Section 2 reviews the related literature. Section 3 introduces the model. Section 4 explains our calibration. Section 5 compares the performance of the model with the data. Section 6 presents the results. Section 7 discusses the role of asset testing. Section 8 relates our results to the recent empirical findings. Section 9 concludes.

\section{Related literature}

Our paper is related to several strands of literature. Our positive analysis is motivated by the literature studying the labor supply effects of public means-tested programs (for an extensive review, see Moffitt, 2002). A subset of this literature focuses on the Medicaid program. Most of these studies use data prior to 1996, when adult eligibility for Medicaid was tied to eligibility for another welfare program, Aid for Families with Dependent

\footnotetext{
${ }^{4}$ The mechanism behind work-dependent asset testing is analogous to the effect of earnings-dependent wealth taxation advocated in several studies of optimal taxation (see, for example, Kocherlakota (2005) and Albansei and Sleet (2006)).
} 
Children (AFDC). ${ }^{5,6}$ The close link between the two programs made it difficult to isolate the effect of Medicaid on labor supply, and different identification strategies were used. Moffitt and Wolfe (1992) exploit the variation in the valuation of Medicaid benefits and show that Medicaid has a significant negative effect on labor force participation. Blank (1989), Winkler (1991) and Montgomery and Navin (2000) use variations in the generosity of Medicaid by state to evaluate its effect on labor supply. The first study finds no effect, while the last two studies find small effects on labor force participation. Yelowitz (1995) exploits the delinking of Medicaid from AFDC for children in the late 1980s and finds that this policy had a positive effect on labor force participation of mothers. Decker (1993) and Strumpf (2011) examine the effects of the introduction of the Medicaid program in the late 1960s and early 1970s on labor force participation; both studies find no effect. Dave et al. (2013) study the expansion of Medicaid to cover the costs of pregnancy and childbirth that happened in the late 1980s and find that this policy significantly decreased the probability that a woman who had recently given birth was employed. Overall, the literature based on pre-1996 data provides mixed evidence on the effects of Medicaid on labor supply. However, there is evidence that the decision to participate in welfare programs was noticeably affected by the availability of health insurance (Ellwood and Adams, 1990; Moffitt and Wolfe, 1992; Decker, 1993).

After the welfare reform of 1996, Medicaid and AFDC were separated and states were allowed to determine their Medicaid eligibility criteria. To our knowledge, four studies examine the effect of Medicaid on labor supply using data from after the welfare reform of 1996. Garthwaite et al. (2014) examine the consequences of a sharp reduction of the state Medicaid expansion program in Tennessee in 2005, when a large number of people were disenrolled within a period of less than a year. They find a significant increase in employment among the group who lost coverage. Dague et al. (2013) study the Medicaid expansion program in Wisconsin and find that it significantly reduces labor supply among its enrollees. Baicker et al. (2014) use the data from the Oregon Health Insurance experiment and find that public insurance does not affect labor supply. In Section 8, we discuss how our results can reconcile these opposite findings. Finally, Pohl (2011) estimates a structural model using variation in Medicaid policies across states and finds that some groups of population are significantly less likely to work to be eligible for Medicaid. Similar to the latter study, our paper addresses this question in a structural framework using post-1996 data. However, we allow for the coexistence of self-insurance, several types of private health insurance and public insurance. We show that the interaction of self-insurance and labor supply distortions is important for our

\footnotetext{
${ }^{5}$ Currently this program is substituted by the Temporary Assistance for Needy Families (TANF).

${ }^{6}$ At the end of the 1980s, Medicaid was expanded to cover pregnant women regardless of their participation in welfare.
} 
normative analysis.

The normative analysis of our paper is related to the literature studying how to efficiently provide insurance in dynamic economies with private information (this literature is often referred to as New Dynamic Public Finance (NDPF)). ${ }^{7}$ A primary focus of these studies is constrained-efficient allocations that solve the planning problem with incentive compatibility constraints arising from information asymmetry. These allocations imply that marginal decisions of agents should be distorted compared with the case of full information. In particular, savings should be discouraged by creating a wedge between the intertemporal marginal rate of substitution and the aggregate return on capital. This is done to minimize the adverse effect of savings on work incentives. Studies that derive how optimal allocations can be implemented show that in certain environments, the optimal wedge on savings can be achieved by asset testing (Golosov and Tsyvinski, 2006) or by wealth taxes that negatively depend on labor income (Kocherlkota, 2005; Albanesi and Sleet, 2006). The former study shows that introducing asset testing to disability insurance results in substantial welfare gains. Based on the findings of these studies, we provide a quantitative analysis of the effects of uniform asset testing and asset testing that depends on labor supply decisions.

Methodologically, we relate to two groups of studies. First, we relate to models with incomplete labor markets augmented by health and medical expense uncertainty and allowing for endogenous health insurance decisions (Kitao and Jeske, 2009, Hansen et al., 2014, Hsu, 2013, Pashchenko and Porapakkarm, 2013). Second, we relate to lifecycle structural models featuring health uncertainty (Capatina, 2015, De Nardi, French, Jones, 2010, French, 2005, Nakajima and Telyukova, 2011). Following the first group of studies, we use a general equilibrium framework, meaning that all aggregate variables (e.g., the ESHI premium and taxes) are endogenous. Similar to the second group of studies, we allow for rich heterogeneity and impose a strict discipline on the model by requiring it to reproduce the behavior of each subgroup of agents as in the data.

\section{Baseline Model}

\subsection{Households}

\subsubsection{Demographics and preferences}

The economy is populated by overlapping generations of individuals. A model period is one year. ${ }^{8}$ An individual lives to a maximum of $N$ periods. During the first $R-1$

\footnotetext{
${ }^{7}$ Kocherlakota (2010) and Golosov, Tsyvinsky and Werning (2010) provide an extensive review.

${ }^{8}$ In most states, the renewal period for Medicaid is 12 months. A typical private health insurance contract also lasts for one year.
} 
periods of life, an individual can choose whether to work, and at age $R$, all individuals retire.

At age $t$, an agent's health condition $h_{t}$ can be either good $\left(h_{t}=1\right)$ or bad $\left(h_{t}=0\right)$. Health condition evolves according to an age-dependent Markov process, $\mathcal{H}_{t}\left(h_{t} \mid h_{t-1}\right)$. Health affects productivity, survival probability, and medical expenses. In addition, unhealthy individuals can become disabled.

An individual is endowed with one unit of time that can be used for either leisure or work. Labor supply $\left(l_{t}\right)$ is indivisible; $l_{t} \in\{0, \bar{l}\} .{ }^{9}$ Work brings disutility modeled as a fixed cost of leisure $\phi_{w}$. We assume the Cobb-Douglas specification for preferences over consumption and leisure:

$$
u\left(c_{t}, l_{t}\right)=\frac{\left(c_{t}^{\chi}\left(1-l_{t}-\phi_{w} \mathbf{1}_{\left\{l_{t}>0\right\}}\right)^{1-\chi}\right)^{1-\sigma}}{1-\sigma}
$$

where $\mathbf{1}_{\{.\}}$is an indicator function mapping to one if its argument is true. Here, $\chi$ is a parameter determining the relative weight of consumption, and $\sigma$ is the risk-aversion over the consumption-leisure composite.

Agents discount the future at rate $\beta$ and survive until the next period with conditional probability $\zeta_{t}^{h}$, which depends on age and health. We assume that the savings of households who do not survive are taxed away by the government. The population grows at rate $\eta$.

\subsubsection{Medical expenditures and health insurance}

Each period, an agent faces a medical expenditure shock. The realized medical expense shock $\left(x_{t}\right)$ depends on age, health condition, and previous medical expense. More specifically, we assume that medical expenditure shock evolves according to a three-state Markov process, and the value of each state depends on age $(t)$ and health condition $\left(h_{t}\right)$. The transition matrix $\mathcal{G}_{t}\left(x_{t} \mid x_{t-1}\right)$ is age-dependent.

Every non-disabled individual of a working age can buy health insurance against medical shocks in the individual health insurance market. The price of health insurance in the individual market depends on the expected medical expenses, thus being a function of age, health condition and medical expense realized in the previous period. We denote the individual market price as $p_{I}\left(h_{t-1}, x_{t-1}, t\right)$.

\footnotetext{
${ }^{9}$ We assume indivisible labor supply because the evidence that low-income earners demonstrate significant response to public policies along the extensive margin is more prevalent than is such evidence for the intensive margin response (Heckman, 1993, Kleven and Kreiner, 2005, Saez, 2002). In addition, in the data, the difference in labor supply between the healthy and the unhealthy is more pronounced along the extensive margin. In our sample, conditional on working, the average worked hours are 2053 and 2174 for the unhealthy and the healthy, respectively, whereas the median worked hours is 2080 for both the healthy and the unhealthy.
} 
Every period, a working-age individual receives an offer to buy employer-sponsored health insurance (ESHI) with probability $\operatorname{Prob}_{t}$, which depends on age, income, and health. ${ }^{10}$ The variable $g_{t}$ characterizes the status of the offer: $g_{t}=1$ if an individual gets an offer, and $g_{t}=0$ if he does not. All participants of the employer-based pool are charged the same premium $p$ regardless of their health and age. Since an employer who offers ESHI pays a fraction $\psi$ of this premium, a worker who chooses to buy group insurance only pays $\bar{p}$ where:

$$
\bar{p}=(1-\psi) p
$$

Low-income non-disabled individuals of a working age can obtain health insurance from Medicaid for free. There are two pathways to qualify for Medicaid. First, an individual is eligible if his total income is below the threshold $y^{\text {cat }}$ and his assets are less than the limit $k^{\text {cat }}$. We call this pathway "categorical eligibility". ${ }^{11}$ Second, an individual can become eligible through the Medically Needy program. This happens if his total income minus the out-of-pocket medical expenses is below the threshold $y^{M N}$ and his assets are less than the limit $k^{M N}$. We call this pathway "eligibility based on medical need".

All types of insurance contracts - group, individual, and public - provide only partial insurance against medical expenditure shocks. We denote by $q\left(x_{t}, i_{t}\right)$ the fraction of medical expenditures covered by an insurance contract. This fraction is a function of medical expenditures and insurance choice $\left(i_{t}\right)$.

Disabled and retired individuals are covered by the Medicare program. ${ }^{12}$ The Medicare program pays a fraction $q_{M C R}$ of medical costs.

\footnotetext{
${ }^{10}$ This assumption is used to replicate the empirical fact that healthy and high-income people are much more likely to be covered by ESHI. Note that health insurance is part of the overall compensation package and that healthier individuals, on average, receive better compensation (the so-called incomehealth gradient; see Cutler, Lleras-Muney and Vogl (2011) for a review). The direction of causality between health and probability to be covered by ESHI can run both ways; healthier individuals receive better compensation or individuals covered by ESHI become healthier. For model tractability, we do not model the endogenous evolution of health. What is important for our analysis, is to capture the fact that different insurance groups have different health compositions (see Table 4). Assuming that health affects ESHI offer probability allows us to incorporate this mechanism in the model in a tractable way.

${ }^{11}$ Medicaid eligibility can also be linked to family status; the federal regulation requires states to cover certain categories of the population - individuals with dependent children and low-income disabled individuals. We abstract from family status because many states have additional eligibility pathways for childless adults. In 2008, 23 states and the District of Columbia operated programs for low-income childless adults (Klein and Schwartz, 2008). The financing of these programs comes from state funding or through Medicaid $\S 1115$ waivers. In our sample, $43 \%$ of non-disabled Medicaid beneficiaries do not have dependent children (defined as children younger than 18 years of age). Thus, introducing a tight link between Medicaid eligibility and family status can significantly underestimate the extent to which this program is available to some categories of the population.

${ }^{12}$ There is a 24-month waiting period to be covered by Medicare for a new awardee into the Disability Insurance program. We abstract from the waiting period to simplify the problem of disabled individuals.
} 


\subsubsection{Labor income}

The household's earnings are equal to $\widetilde{w} z_{t}^{h} l_{t}$, where $\widetilde{w}$ is effective wage and $z_{t}^{h}$ is idiosyncratic productivity, which takes the following form:

$$
z_{t}^{h}=\lambda_{t}^{h} \Upsilon_{t}
$$

Here, $\lambda_{t}^{h}$ is the deterministic function of age and health condition realized at the end of the previous period, and $\Upsilon_{t}$ is the stochastic shock described in Section 4.9. We allow the household's productivity to be affected by health because in the data, the average labor income of unhealthy workers is significantly lower than the average labor income of healthy workers.

\subsubsection{Disability shock}

Unhealthy individuals of a working age can become disabled with an age-dependent probability $d_{t}$. Because low-income people are more likely to become disabled (Low and Pistaferri, 2015), we allow disability shock to be correlated with the realized productivity in the previous period. We assume that disability is an absorbing state, i.e., an individual who becomes disabled stays disabled (and unhealthy) for the rest of his life. ${ }^{13}$ Disabled individuals have zero productivity $\left(z_{t}^{h}=0\right)$ and thus cannot work. ${ }^{14}$

\subsubsection{Taxation and social transfers}

All households pay an income tax $\mathcal{T}\left(y_{t}\right)$ that consists of two parts: a progressive tax and a proportional tax. ${ }^{15}$ Taxable income $y_{t}$ is based on both labor and capital income. Working households also pay payroll taxes: Medicare tax $\left(\tau_{M C R}\right)$ and Social Security $\operatorname{tax}\left(\tau_{s s}\right)$. The Social Security tax rate for earnings above $\bar{y}_{s s}$ is zero. The U.S. tax code allows households to exclude out-of-pocket medical expenditures (including insurance premiums) that exceed $7.5 \%$ of their income when calculating their taxable

\footnotetext{
${ }^{13}$ We assume that the healthy face zero probability to become disabled $\left(d_{t}=0\right)$ because in the data, very few healthy individuals receive DI benefits or report having work limitations. We discuss this issue more in the calibration section. We assume that disability is an absorbing state because the exit rate from the DI program due to recovery is very low. In 2004 , only $0.9 \%$ of beneficiaries exited the DI program due to recovery (Zayatz, 2011). In this assumption, we follow Golosov and Tsyvinski (2005) and Kitao (2015).

${ }^{14}$ We abstract from possible moral hazard in the DI program (that able individuals can pretend to be disabled), because this would significantly increase the model's complexity; we need to incorporate the decisions to apply for the DI and the entire complexity of the DI screening and award rules. Instead, our goal is to understand the role of asset testing in public transfer programs targeted at low-income non-disabled individuals.

${ }^{15}$ The progressive part approximates the actual income tax schedule in the U.S., whereas the proportional tax represents all other taxes that we do not model explicitly. In this approach we follow Jeske and Kitao (2009).
} 
income. In addition, the ESHI premium $(\bar{p})$ is tax-deductible in both income and payroll tax calculations. Consumption is taxed at a proportional rate of $\tau_{c}$.

We also assume a public safety-net program, $T_{t}^{S I}$. This program guarantees every household a minimum consumption level $\underline{c}$, which reflects the option available to lowincome households in the US and/or households with high medical expenses to rely on general public transfer programs such as food stamps, Supplemental Security Income, and uncompensated care. ${ }^{16}$ For the retired and the disabled, $T_{t}^{S I}$ also includes Medicaid transfers since we do not explicitly model Medicaid insurance for these two groups.

Retired households receive Social Security benefits ss. In practice, these payments depend on the highest 35 years of earnings. To minimize the number of state variables, we allow ss to depend only on the fixed productivity type, which is part of the stochastic component of productivity $\Upsilon_{t}$ (see Section 4.9). More specifically, ss is determined by applying the Social Security benefit formula to the average lifetime earnings over the highest 35 years of earnings of individuals with a particular fixed productivity type.

All disabled individuals receive Disability Insurance (DI) payments. Similar to Social Security benefits, in practice these payments depend on the average earnings before the onset of disability. To avoid keeping track of the history of earnings, we abstract from the heterogeneity in DI income and assume that all disabled individuals receive the same payments $\overline{D I}$ fixed throughout their lifetime.

\subsubsection{Timing of the model}

The timing of the model is as follows. At the beginning of the period, disability shock is realized. Next, individuals who stay able learn their productivity and ESHI offer status. Based on this information, an individual decides his labor supply $\left(l_{t}\right)$ and insurance choice $\left(i_{t}\right)$. If he is categorically eligible, he can choose to enroll in Medicaid $(M)$. If he is not eligible or decides not to enroll in Medicaid, he can choose to buy individual insurance $(I)$, to buy employer-based group insurance $(G)$ if offered, or to remain uninsured $(U)$. At the end of the period, the new health status $\left(h_{t}\right)$ and medical expenses shock $\left(x_{t}\right)$ are realized. At this point, an uninsured household can become eligible for the Medically Needy $(M N)$ program after he has spent down his income to pay his medical expenses until he has reached the level of the Medically Needy eligibility threshold. We use a variable $i_{t}^{M N}$ to indicate whether an uninsured individual becomes eligible for the Medical Needy program after his medical shock is realized; $i_{t}^{M N}=1$ if an individual becomes eligible, otherwise $i_{t}^{M N}=0$. After paying the out-of-pocket medical expenses, an individual chooses his consumption $\left(c_{t}\right)$ and savings for the next period $\left(k_{t+1}\right)$. The problem of disabled and retired individuals is simpler; they only choose

\footnotetext{
${ }^{16}$ In $200485 \%$ of the uncompensated care were paid by the government. The major portion was from the disproportionate share hospital (DSH) payment (Kaiser Family Foundation, 2004).
} 
consumption and savings for the next period.

\subsubsection{Optimization problem}

Non-disabled individuals of a working age $(t<R)$. At the beginning of each period, the state variables for a non-disabled household are capital ( $k_{t} \in \mathbb{K}=R^{+} \cup\{0\}$ ), health and medical shock realized at the end of the last period $\left(h_{t-1} \in \mathbb{H}=\{0,1\}\right.$, $\left.x_{t-1} \in \mathbb{X}=R^{+} \cup\{0\}\right)$, idiosyncratic labor productivity $\left(z_{t}^{h} \in \mathbb{Z}=R^{+}\right)$, ESHI offer status $\left(g_{t} \in \mathbb{G}=\{0,1\}\right)$, and age $(t \in \mathbb{T}=\{1,2, \ldots, R-1\})$. His value function at the beginning of period $t$ is:

$V_{t}\left(k_{t}, h_{t-1}, x_{t-1}, z_{t}^{h}, g_{t}\right)=\max _{l_{t}, i_{H}} \sum_{h_{t}, x_{t}} \mathcal{H}_{t}\left(h_{t} \mid h_{t-1}\right) \mathcal{G}_{t}\left(x_{t} \mid x_{t-1}\right) W_{t}^{\left\{l_{t}, i_{H}\right\}}\left(k_{t}, h_{t-1}, x_{t-1}, z_{t}^{h}, g_{t} ; h_{t}, x_{t}\right)$

where

$$
\begin{aligned}
& W_{t}^{\left\{l_{t}, i_{H}\right\}}\left(k_{t}, h_{t-1}, x_{t-1}, z_{t}^{h}, g_{t} ; h_{t}, x_{t}\right)= \\
& \max _{c_{t}, k_{t+1}} u\left(c_{t}, l_{t}\right)+\beta \zeta_{t}^{h}\left(\left(1-d_{t+1}\right) E_{t} V_{t+1}\left(k_{t+1}, h_{t}, x_{t}, z_{t+1}^{h}, g_{t+1}\right)+d_{t+1} V_{t+1}^{D}\left(k_{t+1}, x_{t}\right)\right)
\end{aligned}
$$

subject to

$$
\begin{aligned}
& k_{t}(1+r)+\widetilde{w} z_{t}^{h} l_{t}+T^{S I}=k_{t+1}+\left(1+\tau_{c}\right) c_{t}+\operatorname{Tax}+P_{t}+X_{t} \\
& \widetilde{w}=\left\{\begin{array}{lll}
w & ; & \text { if } g_{t}=0 \\
\left(w-c_{E}\right) & ; & \text { if } g_{t}=1
\end{array}\right\} \\
& P_{t}= \begin{cases}0 & ; \text { if } i_{t} \in\{U, M\} \\
p_{I}\left(h_{t-1}, x_{t-1}, t\right) & ; \text { if } i_{t} \in\{I\} \\
\bar{p} & ; \text { if } i_{t} \in\{G\}\end{cases} \\
& T_{t}^{S I}=\max \left(0,\left(1+\tau_{c}\right) \underline{c}+\operatorname{Tax}+P_{t}+X_{t}-k_{t}(1+r)-\widetilde{w} z_{t}^{h} l_{t}\right) \\
& \operatorname{Tax}=\mathcal{T}\left(y_{t}\right)+\tau_{M C R}\left(\widetilde{w} z_{t}^{h} l_{t}-\bar{p} \mathbf{1}_{\left\{i_{t}=G\right\}}\right)+\tau_{s s} \min \left(\widetilde{w} z_{t}^{h} l_{t}-\bar{p} \mathbf{1}_{\left\{i_{t}=G\right\}}, \bar{y}_{s s}\right) \\
& y_{t}=\max \left(0, k_{t} r+\widetilde{w} z_{t}^{h} l_{t}-\bar{p} \mathbf{1}_{\left\{i_{t}=G\right\}}-\max \left(0, X_{t}+p_{I}\left(h_{t-1}, x_{t-1}, t\right) \mathbf{1}_{\left\{i_{t}=I\right\}}-0.075\left(k_{t} r+\widetilde{w} z_{t}^{h} l_{t}\right)\right)\right)
\end{aligned}
$$


$X_{t}= \begin{cases}x_{t}\left(1-q\left(x_{t}, i_{t}\right)\right) & \text { if } i_{t}=\{M, I, G\} \\ x_{t}\left(1-q\left(x_{t}, M\right)\right)+\max \left(0, k_{t} r+\widetilde{w} z_{t}^{h} l_{t}-y^{M N}\right) q\left(x_{t}, M\right) & \text { if } i_{t}=\{U\} \text { and } i_{t}^{M N}=1 \\ x_{t} & \text { if } i_{t}=\{U\} \text { and } i_{t}^{M N}=0\end{cases}$

An individual is eligible for Medicaid if

$k_{t} r+\widetilde{w} z_{t}^{h} l_{t} \leq y^{\text {cat }} \quad$ and $k_{t} \leq k^{c a t} \quad$ for categorial eligibility,

$k_{t} r+\widetilde{w} z_{t}^{h} l_{t}-x_{t} \leq y^{M N}$ and $k_{t} \leq k^{M N}$ for the Medically Needy program.

$W_{t}^{\left\{l_{t}, i_{H}\right\}}$ is the interim value function conditional on the labor supply and insurance choices after the new health condition and medical expenses are realized. The conditional expectation on the right-hand side of Eq. (3) is over $\left\{z_{t+1}^{h}, g_{t+1}\right\} . V_{t+1}^{D}$ is the value function of an individual who becomes disabled next period. Eq. (4) is the budget constraint. In Eq. (5), $w$ is wage per effective labor unit. If a household has an ESHI offer, his employer pays part of his insurance premium. We assume that the firm offering ESHI passes the costs of the employer's contribution to its workers by deducting an amount $c_{E}$ from the wage per effective labor unit. In Eq. (8), the first term is income tax and the last two terms are payroll taxes. ${ }^{17}$ Eq. (10) describes out-of-pocket medical expenses, $X_{t}$, which depend on insurance status. It takes into account that an uninsured person who becomes eligible for the Medically Needy program has to first spend down his income before public insurance starts paying for his medical expenses.

Disabled individuals. The state variables of a disabled individual are assets $\left(k_{t}\right)$, medical shock $\left(x_{t-1}\right)$ and age $(t)$. Because a disabled individual is unhealthy $\left(h_{t}=0\right)$ and disability is an absorbing state, his value function is:

$$
\begin{gathered}
V_{t}^{D}\left(k_{t}, x_{t-1}\right)=\sum_{x_{t}} \mathcal{G}_{t}\left(x_{t} \mid x_{t-1}\right) W_{t}^{D}\left(k_{t}, x_{t}\right) \\
W_{t}^{D}\left(k_{t}, x_{t}\right)=\max _{c_{t}, k_{t+1}} u(c, 0)+\beta \zeta_{t}^{h} V_{t+1}^{D}\left(k_{t+1}, x_{t}\right)
\end{gathered}
$$

subject to:

$$
\begin{gathered}
k_{t}(1+r)+\overline{D I}+T^{S I}=k_{t+1}+\left(1+\tau_{c}\right) c_{t}+\mathcal{T}\left(y_{t}\right)+p_{M C R}+x_{t}\left(1-q_{M C R}\right), \\
T_{t}^{S I}=\max \left(0,\left(1+\tau_{c}\right) \underline{c}+\mathcal{T}\left(y_{t}\right)+p_{M C R}+x_{t}\left(1-q_{M C R}\right)-k_{t}(1+r)-\overline{D I}\right) \\
y_{t}=k_{t} r+\overline{D I}-\max \left(0, x_{t}\left(1-q_{M C R}\right)-0.075\left(k_{t} r+\overline{D I}\right)\right) .
\end{gathered}
$$

\footnotetext{
${ }^{17}$ In practice, employers contribute $50 \%$ of Medicare and Social Security taxes. For simplicity, we assume that employees pay $100 \%$ of payroll taxes.
} 
Retired non-disabled individuals $(t \geq R)$. For a retired household who did not receive disability shock during the working stage of his life cycle, the state variables are assets $\left(k_{t}\right)$, health $\left(h_{t-1}\right)$, medical shock $\left(x_{t-1}\right)$, and age $(t) .{ }^{18}$ The value function of a retired household is:

$$
V_{t}\left(k_{t}, h_{t-1}, x_{t-1}\right)=\sum_{h_{t}, x_{t}} \mathcal{H}_{t}\left(h_{t} \mid h_{t-1}\right) \mathcal{G}_{t}\left(x_{t} \mid x_{t-1}\right) W_{t}\left(k_{t}, h_{t}, x_{t}\right)
$$

where

$$
W_{t}\left(k_{t}, h_{t}, x_{t}\right)=\max _{c_{t}, k_{t+1}} u(c, 0)+\beta \zeta_{t}^{h} V_{t+1}\left(k_{t+1}, h_{t}, x_{t}\right)
$$

subject to:

$$
\begin{gathered}
k_{t}(1+r)+s s+T^{S I}=k_{t+1}+\left(1+\tau_{c}\right) c_{t}+\mathcal{T}\left(y_{t}\right)+p_{M C R}+x_{t}\left(1-q_{M C R}\right) \\
T_{t}^{S I}=\max \left(0,\left(1+\tau_{c}\right) \underline{c}+\mathcal{T}\left(y_{t}\right)+p_{M C R}+x_{t}\left(1-q_{M C R}\right)-k_{t}(1+r)-s s\right) \\
y_{t}=k_{t} r+s s-\max \left(0, x_{t}\left(1-q_{M C R}\right)-0.075\left(k_{t} r+s s\right)\right)
\end{gathered}
$$

Distribution of households. To simplify the notation, let $\mathbb{S}$ define the space of a household's state variables at the end of each period; $\mathbb{S}^{\mathbb{W}}=\mathbb{K} \times \mathbb{H} \times \mathbb{X} \times \mathbb{Z} \times \mathbb{G} \times \mathbb{H} \times \mathbb{X} \times \mathbb{T}$ for working-age non-disabled individuals, $\mathbb{S}^{\mathbb{R}}=\mathbb{K} \times \mathbb{H} \times \mathbb{X} \times \mathbb{T}$ for retired non-disabled individuals, and $\mathbb{S}^{\mathbb{D}}=\mathbb{K} \times \mathbb{X} \times \mathbb{T}$ for disabled individuals. Let $\mathbf{s} \in \mathbb{S}=\mathbb{S}^{\mathbb{W}} \cup \mathbb{S}^{\mathbb{R}} \cup \mathbb{S}^{\mathbb{D}}$, and denote by $\Gamma(\mathbf{s})$ the distribution of households over the state-space.

\subsection{Production sector}

There are two stand-in firms which act competitively. Their production functions are Cobb-Douglas, $A K^{\alpha} L^{1-\alpha}$, where $K$ and $L$ are aggregate capital and aggregate labor and $A$ is the total factor productivity. The first stand-in firm offers ESHI to its workers, but the second one does not. Under competitive behavior, the second firm pays each employee his marginal product of labor. Because capital is freely allocated between the two firms, the Cobb-Douglas production function implies that the capital-labor ratios of both firms are the same. Consequently, we have

$$
\begin{aligned}
& w=(1-\alpha) A K^{\alpha} L^{-\alpha}, \\
& r=\alpha A K^{\alpha-1} L^{1-\alpha}-\delta,
\end{aligned}
$$

\footnotetext{
${ }^{18}$ As explained in Section 3.1.5, Social Security payments $s s$ depend on the fixed productivity type; thus, fixed productivity is also part of the state variables for retired households. We omit it from the description of the optimization problem to simplify the notation.
} 
where $\delta$ is the depreciation rate.

The first firm has to partially finance the health insurance premium for its employees. These costs are fully passed on to its employees through a wage reduction. In specifying this wage reduction, we follow Jeske and Kitao (2009). The first firm subtracts an amount $c_{E}$ from the marginal product per effective labor unit. The zero profit condition implies

$$
c_{E}=\frac{\psi p \int_{\mathbf{s} \in \mathbb{S} W} \mathbf{1}_{\left\{i_{t}=G\right\}} \Gamma(\boldsymbol{s})}{\int_{\mathbf{s} \in \mathbb{S} W} l_{t} z_{t}^{h} \mathbf{1}_{\left\{g_{t}=1\right\}} \Gamma(\boldsymbol{s})} .
$$

The numerator is the total contributions toward the insurance premiums paid by the first firm. The denominator is the total effective labor in the first firm.

\subsection{Insurance sector}

Health insurance companies in both private and group markets act competitively but incur administrative costs when issuing an insurance contract. We assume that insurers can observe all state variables that determine the future medical expenses of individuals. ${ }^{19}$ This assumption, together with the zero profit conditions, allows us to write insurance premiums as follows:

$$
p_{I}\left(h_{t-1}, x_{t-1}, t\right)=\gamma E M_{t}\left(h_{t-1}, x_{t-1}\right)+\varphi^{h}
$$

for the non-group insurance market and

$$
p=\gamma \frac{\int_{\mathbf{s} \in \mathbb{S}^{W}} \mathbf{1}_{\left\{i_{t}=G\right\}} E M_{t}\left(h_{t-1}, x_{t-1}\right) \Gamma(s)}{\int_{\mathbf{s} \in \mathbb{S} W} \mathbf{1}_{\left\{i_{t}=G\right\}} \Gamma(s)}
$$

for the group insurance market. Here, $E M_{t}\left(h_{t-1}, x_{t-1}\right)$ is the expected medical cost to an insurance company for an individual aged $t$ whose last period health condition and medical expense shock are $h_{t-1}$ and $x_{t-1}$, respectively:

$$
E M_{t}\left(h_{t-1}, x_{t-1}\right)=\sum_{h_{t}, x_{t}} x_{t} q\left(x_{t}, i_{t}\right) \mathcal{G}_{t}\left(x_{t} \mid x_{t-1}\right) \mathcal{H}_{t}\left(h_{t} \mid h_{t-1}\right) ; \quad i_{t} \in\{I, G\}
$$

The premium in the non-group insurance market is based on the expected medical expenditure of an individual buyer. The premium for group insurance is based on the weighted average of the expected medical costs of those who buy group insurance. In

\footnotetext{
${ }^{19}$ Before the Affordable Care Act of 2014, most states allowed insurance firms to medically underwrite applicants for health insurance.
} 
Eqs. (23) and (24), $\gamma$ is a markup on premiums due to administrative costs. For individual insurance, there is a fixed cost $\varphi^{h}$ representing the underwriting and other overhead costs. $^{20}$ Note that there is no fixed cost in the group market because there is no underwriting at the individual level and because overhead costs are spread over a large number of pool participants. We allow the fixed cost to differ by health to capture the following. First, underwriting an unhealthy applicant can take more resources, e.g., to gather more detailed medical records. Second, unhealthy individuals face additional frictions in the individual market, for example, searching costs or a probability to be denied coverage due to pre-existing conditions. ${ }^{21}$

\subsection{Government constraint}

We assume that the government runs a balanced budget. This assumption implies that

$$
\begin{aligned}
& \int_{\mathbf{s} \in \mathbb{S}_{\mathbb{W}}}\left(\tau_{M C R}\left(\widetilde{w} z_{t}^{h} l_{t}-\bar{p} \mathbf{1}_{\left\{i_{t}=G\right\}}\right)+\tau_{s s} \min \left(\widetilde{w} z_{t}^{h} l_{t}-\bar{p} \mathbf{1}_{\left\{i_{t}=G\right\}}, \bar{y}_{s s}\right)\right) \Gamma(\mathbf{s})+ \\
& \int_{\mathbf{s} \in \mathbb{S}}\left(\tau_{c} c_{t}+\mathcal{T}\left(y_{t}\right)\right) \Gamma(\mathbf{s})+\int_{\mathbf{s} \in \mathbb{S}^{\mathbb{R}} \cup \mathbb{S}^{\mathbb{D}}} p_{M C R} \Gamma(\mathbf{s})+\int_{\mathbf{s} \in \mathbb{S}} k_{t+1}\left(1-\zeta_{t}^{h}\right) \Gamma(\mathbf{s})-G o v= \\
& \int_{\mathbf{s} \in \mathbb{S}} T^{S I} \Gamma(\mathbf{s})+\int_{\mathbf{s} \in \mathbb{S}^{\mathbb{R}}} s s \Gamma(\mathbf{s})+\int_{\mathbf{s} \in \mathbb{S}^{\mathbb{D}}} \overline{D I} \Gamma(\mathbf{s})+\int_{\mathbf{s} \in \mathbb{S}^{\mathbb{R}} \cup \mathbb{S}^{\mathbb{D}}} x_{t} q_{M C R} \Gamma(\mathbf{s})+ \\
& \int_{\mathbf{s} \in \mathbb{S}_{\mathbb{W}}}\left(x_{t}-X_{t}\right) \mathbf{1}_{\left\{i_{t}=M \text { or }\left(i_{t}=U \& i_{t}^{M N}=1\right)\right\}} \Gamma(\mathbf{s})
\end{aligned}
$$

The left-hand side is the total tax revenue from all households (including assets of the deceased) net of the exogenous government expenditures (Gov). The first term on the right-hand side is the cost of guaranteeing the minimum consumption floor for all households. The second to forth terms are the expenditures on Social Security and Medicare programs (both for the disabled and the retired). The last term is the cost of Medicaid including the Medically Needy program for working-age households.

\footnotetext{
${ }^{20}$ The proportional markup $\gamma$ can also be interpreted as the extra profit of insurance companies if the health insurance market is not perfectly competitive. The proportional markup and fixed costs are important when we bring the model to the data; if insurance contracts have no loads or fixed costs, the model will overestimate the empirical profiles of individual insurance purchases.

${ }^{21}$ Equivalently, we could set fixed cost to be the same for the healthy and the unhealthy, and assume instead that unhealthy individuals were subject to persistent pre-existing condition shocks. However, the explicit modeling of pre-existing conditions would require adding an additional state variable.
} 


\subsection{Definition of stationary competitive equilibrium}

Given the government programs $\left\{\underline{c}, s s, \overline{D I}, q_{M C R}, p_{M C R}, y^{c a t}, k^{c a t}, y^{M N}, k^{M N}, G o v\right\}$, the fraction of medical costs covered by private insurers and Medicaid $\left\{q\left(x_{t}, i_{t}\right)\right\}$, and the employers' contribution $(\psi)$, the competitive equilibrium of this economy consists of a set of time-invariant prices $\left\{w, r, p, p_{I}\left(h_{t-1}, x_{t-1}, t\right)\right\}$, wage reduction $\left\{c_{E}\right\}$, households' value functions $\left\{V_{t}(\boldsymbol{s}), V_{t}^{D}(\mathbf{s})\right\}$, decision rules $\left\{k_{t+1}(s), c_{t}(\boldsymbol{s}), l_{t}(\mathbf{s}), i_{t}(\boldsymbol{s})\right\}$ for workingage non-disabled households and $\left\{c_{t}(s), k_{t+1}(s)\right\}$ for retired and disabled individuals, and tax functions $\left\{\mathcal{T}(y), \tau_{\text {med }}, \tau_{s s}, \tau_{c}\right\}$ such that the following conditions are satisfied:

1. Given a set of prices and the tax functions, the decision rules solve the households' optimization problems in Eqs. (2), (12), and (16).

2. Wage $(w)$ and rent $(r)$ satisfy Eqs. (20) and (21), where

$$
K=\int_{\mathbf{s} \in \mathbb{S}} \zeta_{t}^{h} k_{t+1} \Gamma(\boldsymbol{s}) ; \quad L=\int_{\mathbf{s} \in \mathbb{S}^{\mathbb{W}}} z_{t}^{h} l_{t} \Gamma(\boldsymbol{s}) .
$$

3. $c_{E}$ satisfies Eq. (22); thus, the firm offering ESHI earns zero profit.

4. The non-group insurance premiums $p_{I}\left(h_{t-1}, x_{t-1}, t\right)$ satisfy Eq. (23), and the group insurance premium satisfies Eq. (24); therefore, health insurance companies earn zero profit.

5. The tax functions $\left\{\mathcal{T}(y), \tau_{M C R}, \tau_{s s}, \tau_{c}\right\}$ balance the government budget Eq. (25).

\section{Data and calibration}

We calibrate the model using the Medical Expenditure Panel Survey (MEPS) dataset. The MEPS collects detailed records on demographics, income, medical costs and insurance for a nationally representative sample of households. It consists of two-year overlapping panels and covers the period from 1996 to 2013. For each wave, each person is interviewed five rounds over the two-year period. We use fourteen waves of MEPS (1999-2013). We use the cross-sectional weights and longitudinal weights provided in MEPS for the cross-sectional and longitudinal pools, respectively. Because each wave is a representation of the population in that year, when pooling several years (or waves) together, the weight of each individual was divided by the number of years (or waves). We use 2004 as the base year. All level variables were normalized to the base year using the Consumer Price Index (CPI). 


\subsection{Sample selection}

In MEPS, people are linked into one household based on eligibility for coverage under a typical family insurance plan. This Health Insurance Eligibility Unit (HIEU) defined in the MEPS dataset corresponds to our definition of a household. In our model, a household is a single unit; therefore, we include only heads of the HIEU. We define the head as the person with the highest income in the HIEU. ${ }^{22}$

We start by constructing a two-year balanced panel that includes household heads who are at least 24 years old and who have no missing information on self-reported health status, health insurance status, and medical expenses. There are 86,797 individuals (or 173,594 individual-year observations) meeting our criteria. We drop 999 individuals who are covered by public health insurance that is neither Medicaid nor Medicare. In addition, we drop 1,577 individuals who are younger than 62 years old and do not receive Social Security income but report receiving Medicare. We do this because Medicare covers non-elderly people only if they are awarded social security disability insurance benefits. ${ }^{23}$ The resulting sample size is 84,221 individuals (or 168,442 individual-year observations). Table 1 shows the sample size by wave.

\begin{tabular}{|c|c|c|c|c|c|c|c|c|c|c|c|c|c|c|}
\hline year & $99 / 00$ & $00 / 01$ & $01 / 02$ & $02 / 03$ & $03 / 04$ & $04 / 05$ & $05 / 06$ & $06 / 07$ & $07 / 08$ & 08/09 & $09 / 10$ & $10 / 11$ & $11 / 12$ & $12 / 13$ \\
\hline sample size & 4,790 & 3,814 & 7,682 & 5,797 & 5,930 & 5,891 & 5,732 & 6,188 & 4,693 & 6,796 & 6,447 & 5,749 & 7,465 & 7,247 \\
\hline
\end{tabular}

Table 1: Number of individuals in our sample by wave of the MEPS (1999-2013)

\subsection{Demographics, preferences and technology}

In the model, agents are born at age 25 and can live to a maximum age of 99 . Since the model period is one year, the maximum lifespan $N$ is 75 . Agents retire at the age of 65 , so $R$ is 41 . The population growth rate was set to $0.7 \%$ to match the fraction of people older than 65 in the data.

We set the consumption share in the utility function $\chi$ to 0.6 , which is within the range estimated by French (2005). ${ }^{24}$ The parameter $\sigma$ is set to 2.50 , which facilitates matching the age profile of the fraction of people with individual insurance. This corresponds to

\footnotetext{
${ }^{22}$ If we do not limit our sample to the heads of the households, we have to include dependents whose only source of income is transfers from a spouse. There are two ways to model correctly the behavior of these individuals: i) consider intrafamily decisions, ii) allow individuals to receive exogenous non-earned income that approximates transfers from a spouse. The first approach will make our computational analysis intractable, and the second approach cannot be taken in a general equilibrium environment.

${ }^{23}$ There are several exceptions to this rule. For example, individuals with end stage renal disease can obtain Medicare without being enrolled in the Disability Insurance program. However, these exceptions are relatively rare.

${ }^{24}$ Given that we have an indivisible labor supply, we cannot pin down this parameter using a moment in the data.
} 
the risk aversion over consumption equal to $1.90\left(-c u_{c c} / u_{c}=1-\chi(1-\sigma)\right)$. The discount factor $\beta$ is set to 0.9965 to match the capital-output ratio of 2.7 , which is the average ratio of private fixed assets plus consumer durables to GDP from 2000 to 2011 (Bureau of Economic Analysis). We set the labor supply of those who choose to work $(\bar{l})$ to 0.4 . We define a person as employed if he earns at least $\$ 2,678$ per year in base year dollars (this corresponds to working at least 10 hours per week and earning a minimum wage of $\$ 5.15$ per hour). Fixed leisure costs of work $\phi_{w}$ are calibrated to match the employment profiles among healthy individuals.

The Cobb-Douglas function parameter $\alpha$ is set at 0.33 , which corresponds to the capital income share in the US. The annual depreciation rate $\delta$ is set at 0.085 to match the average ratio of private investments plus durable consumption expenses to GDP, $0.23 \%$. (In a steady-state, $\delta=\frac{I / Y}{K / Y}=\frac{0.23}{2.7}$.) Total factor productivity $A$ is normalized so that the total output equals one in the baseline model.

\subsection{Health shock and disability shock}

In MEPS, a person's self-reported health status is coded as 1 for excellent, 2 for very good, 3 for good, 4 for fair and 5 for poor. We classify a person as being in bad health if his average health score over that year is greater than $3 .^{25}$

The health transition probability is parameterized as a polynomial function of age as follows:

$$
\begin{aligned}
& \mathcal{H}_{t}\left(h_{t}=0 \mid h_{t-1}=1\right)=\pi_{t}^{G B}=a_{0}^{G}+a_{1}^{G} t+a_{2}^{G} t^{2}, \\
& \mathcal{H}_{t}\left(h_{t}=0 \mid h_{t-1}=0\right)=\pi_{t}^{B B}=a_{0}^{B}+a_{1}^{B} t+a_{2}^{B} t^{2} .
\end{aligned}
$$

We estimate the probability to move from good to bad health directly from the data. Specifically, we compute $\pi_{t}^{G B}$ for ages $27,32,37, \ldots, 82,85+$ using a sample in a 5 -year age bracket. For example, to obtain $\pi_{t}^{G B}$ for age 32 , we use the sample in the age bracket 30-34 and measure the fraction of people whose health status changes from good to bad in one year. Then, we estimate $\left\{a_{0}^{G}, a_{1}^{G}, a_{2}^{G}\right\}$ to fit these estimated points. For the transition probability from bad to bad health, we estimate $\left\{a_{0}^{B}, a_{1}^{B}, a_{2}^{B}\right\}$ by matching the fraction of unhealthy people in our model to the fraction of unhealthy people in the data. We could

\footnotetext{
${ }^{25}$ We classify individuals into good and bad health status based on a self-reported health measure. In this approach, we follow other quantitative life-cycle models with health and medical expense uncertainty, e.g., French (2005), De Nardi et al. (2010), Capatina (2015), and Kitao (2009). The self-reported health in MEPS is consistent with a more objective measure of health, the Physical Component Summary (PCS) score, which is based on a 12-item short questionnaire: individuals whom we classify as unhealthy have significantly lower PCS scores. In addition, our approach allows us to combine MEPS and Health and Retirement Study (HRS) when estimating the survival probabilities by health because the latter dataset also contains a self-reported health variable. Attanasio et al. (2011) show that the distribution of self-reported health is similar across the two datasets.
} 
also estimate $\left\{a_{0}^{B}, a_{1}^{B}, a_{2}^{B}\right\}$ directly from the data as we did for parameters $\left\{a_{0}^{G}, a_{1}^{G}, a_{2}^{G}\right\}$. We did not choose this approach because of the small sample size of unhealthy individuals, particulary among younger groups.

To adjust conditional survival probabilities $\zeta_{t}^{h}$ for the difference in health, we follow Attanasio et al. (2011). In particular, we use the Health and Retirement Survey (HRS) to estimate the difference in survival probabilities for people in different health categories and then adjust the male life tables from the Social Security Administration. Appendix $\mathrm{B}$ explains in more detail how we adjust the survival probability.

In our model, disabled individuals are those who permanently lose their productivity and cannot work. To construct a sample of individuals who correspond to this definition, we use two criteria. First, an individual has to receive Social Security income or Supplemental Security Income (variables SSECP and SSIP). Second, an individual has to report having a work limitation in at least one interview round for two consecutive years (variable WRKLIM). MEPS does not have information on whether a person receives Social Security income because he is in the DI program or because he claimed Social Security benefits early. Because of this, we can only identify DI payments for individuals younger than 62 year old (the earliest age at which Social Security benefits can be claimed). Thus, in our calibration, we restrict some targeted age-profiles to ages between 25 and 61 .

We assign the probability to become disabled equal to zero for the healthy. We do this because in MEPS, less than $1 \%$ of individuals whose health is excellent, very good or good between ages 25 and 61 years old report having work limitations or receiving Social Security income. Moreover, conditional on being healthy, the probability to have a work limitation and receive Social Security income in the following year among people aged 25 to 61 years old is only $0.15 \%$.

We specify the probability to receive disability shock as a logistic function:

$$
d_{t}=\frac{\exp \left(a_{0 t}^{D}-a_{1 t}^{D} \log \left(z_{t-1}^{h}\right)\right)}{1+\exp \left(a_{0 t}^{D}-a_{1 t}^{D} \log \left(z_{t-1}^{h}\right)\right)},
$$

where the coefficients depend on age. Because low-income individuals are more likely to become disabled, we allow $d_{t}$ to depend on $z_{t-1}^{h}$. We estimate the parameters of Eq. (26) inside the model as follows. The parameter $a_{0 t}^{D}$ is estimated by matching the fraction of DI recipients in the model to this fraction in the data. The parameter $a_{1 t}^{D}$ is estimated by matching the average DI payments in MEPS $(\$ 4,920)$. We do this in two steps. First, in the US, the DI payments are determined by applying the Social Security benefit formula to the average lifetime earnings before the onset of disability. In our model, to reduce the number of state variables, we use $z_{t-1}^{h}$ to proxy for the average lifetime earnings of an individual before the onset of disability, relying on the fact that the productivity process is highly persistent. Thus, we apply the Social Security benefit formula to the 
last productivity realization $z_{t-1}^{h}$ of a newly disabled individual, which results in the DI payment $D I_{z} \cdot{ }^{26}$ Second, since in our model we abstract from heterogeneity in DI payments (see Section 3.1.5), we define the DI benefits $\overline{D I}$ as the average of $D I_{z}$ over all of the disabled. Thus, the DI payment in our model depends on the composition of the disabled in terms of their previous productivity, and this composition depends on the parameter $a_{1 t}^{D}$. For example, if $a_{1 t}^{D}$ is zero, the probability to receive disability shock does not depend on productivity meaning that high- and low-productivity individuals are equally likely to become disabled. In this case, the DI payment in our model will be too high compared with the data, and $a_{1 t}^{D}$ needs to be adjusted upwards. Note that in our model, all of the disabled are unhealthy, disability is an absorbing state, and disability shock is a function of labor productivity. Because of this, $\left\{a_{0}^{B}, a_{1}^{B}, a_{2}^{B}\right\},\left\{a_{0 t}^{D}, a_{1 t}^{D}\right\}$, labor productivity process $z_{t}^{h}$ and ESHI offer probability should be estimated simultaneously. The estimation of the productivity process and ESHI offer probability are described in Sections 4.8 and 4.9 .

For the initial distribution of the unhealthy and the disabled, we use the distribution of individuals aged 24-26 in the data. Figures (1) and (2) compare the fraction of the unhealthy and the disabled for each age group in our model with the data.

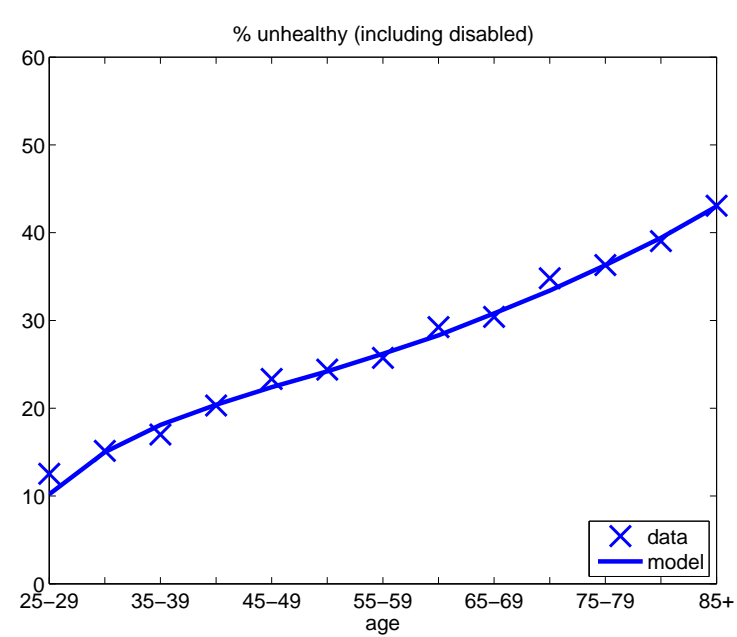

Figure 1: \% of the unhealthy in the population

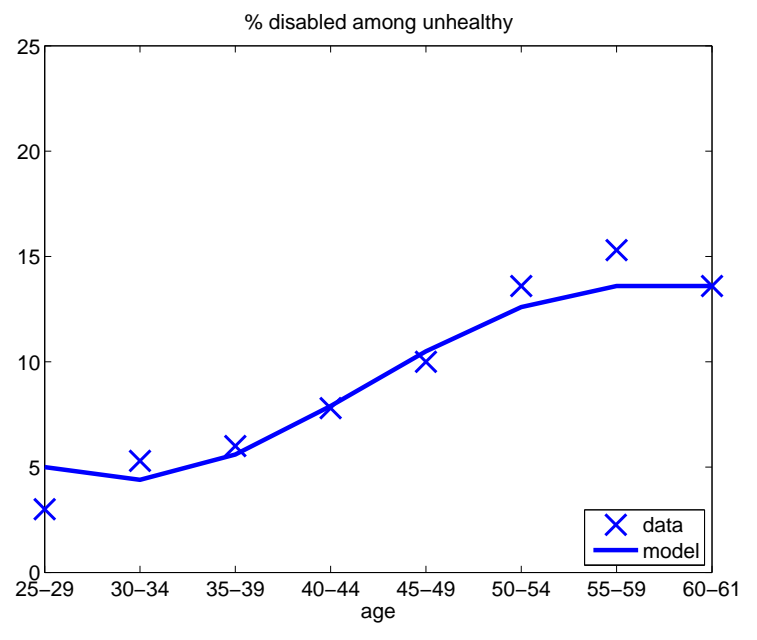

Figure 2: $\%$ of disabled individuals among the unhealthy

\subsection{Taxes and government transfers}

In specifying the tax function $\mathcal{T}(y)$ we use a nonlinear functional form as specified by Gouveia and Strauss (1994), together with a linear income tax $\tau_{y}$ :

$$
\mathcal{T}(y)=a_{0}\left[y-\left(y^{-a_{1}}+a_{2}\right)^{-1 / a_{1}}\right]+\tau_{y} y
$$

\footnotetext{
${ }^{26}$ We use the Social Security benefit formula for 2004 .
} 
The first term captures progressive income tax and is commonly used in the quantitative macroeconomic literature (for example, Conesa and Krueger, 2006; Jeske and Kitao, 2009). In this functional form, $a_{0}$ controls the marginal tax rate faced by the highest income group, $a_{1}$ determines the curvature of marginal taxes, and $a_{2}$ is a scaling parameter. Following Gouveia and Strauss (1994), we set $a_{0}$ and $a_{1}$ to 0.258 and 0.768 , respectively. The parameter $a_{2}$ is used to balance the government budget in the baseline economy. We set the proportional income tax $\tau_{y}$ to $6.66 \%$ to match the fact that around $65 \%$ of tax revenues come from progressive income taxes. In all experimental cases, we adjust the proportional tax $\tau_{y}$ to balance the government budget.

The Medicare, Social Security and consumption tax rates were set to $2.9 \%, 12.4 \%$ and $5.67 \%$, respectively. The maximum taxable income for Social Security $\left(\bar{y}_{s s}\right)$ is set to $\$ 84,900$. The fraction of exogenous government expenses in GDP is $18.8 \%$.

For retired individuals, the Social Security pension payments ss are calculated as follows. For each fixed productivity type, we compute the average labor income over the 35 highest-earning years and then apply the Social Security benefit formula. As explained in Section 3.1.5, we do this to avoid keeping track of the average past earnings as an additional state variable. For disabled individuals, we set $\overline{D I}$ to the average DI payments in MEPS, which is $\$ 4,920$ (see Section 4.3 for more details).

When calibrating the consumption minimum floor $\underline{c}$, we use the fact that this safety net has a significant effect on labor supply decisions, particularly for the unhealthy and for people with low productivity. We set the minimum consumption floor to $\$ 1,540$ to match the employment rate among Medicaid beneficiaries. ${ }^{27}$ Our estimate of the consumption floor is lower compared with other life-cycle models with medical expense shocks, e.g., De Nardi et al. (2010). This is because we explicitly model several safety net programs (Disability Insurance and the Medically Needy programs), which are usually assumed to be part of the minimum consumption guarantee.

The income eligibility threshold for the general Medicaid program $\left(y^{c a t}\right)$ is set to $70.5 \%$ of the Federal Poverty Line (FPL) to match the life-cycle profile of the fraction of people covered by Medicaid. The income eligibility threshold for the Medically Needy program $\left(y^{M N}\right)$ is set to be the same as the threshold for the general Medicaid program $\left(y^{c a t}\right)$. We set the asset test limit for categorical eligibility $\left(k^{c a t}\right)$ to $\$ 26,000$ to match the fraction of Medicaid enrollees aged 51-64 who have assets below $\$ 10,000$. Table 2 compares the asset distribution of Medicaid enrollees aged 51-64 in our model with this

\footnotetext{
${ }^{27} \mathrm{An}$ alternative strategy is to calibrate the minimum consumption floor to match the asset accumulation among poor individuals. Although we do not pursue this strategy, our model can capture well the left tail of the wealth distribution. Among people aged 25-64 in our model, the fraction of people with zero assets, assets below $\$ 2,000, \$ 5,000, \$ 10,000$, and $\$ 20,000$ are $8.9 \%, 13.9 \%, 17.0 \%, 23.4 \%$, and $32.3 \%$, respectively. These fractions in the data are $9.5 \%, 12.8 \%, 16.9 \%, 21.1 \%$, and $27.1 \%$, respectively (Survey of Consumer Finance, 2001-2007).
} 
distribution in HRS. Finally, the asset limit for the Medically Needy program $\left(k^{M N}\right)$ is taken from the data and is set to $\$ 2,000$, which is the median asset limit in states that had the Medically Needy program in 2009. ${ }^{28}$

\begin{tabular}{lcc}
\hline \hline Assets (\$) & Data (HRS 2000-2012) & Baseline model \\
\hline 0 & $37 \%$ & $48 \%$ \\
1,000 & $49 \%$ & $52 \%$ \\
2,000 & $54 \%$ & $56 \%$ \\
5,000 & $63 \%$ & $61 \%$ \\
10,000 & $69 \%$ & $70 \%$ \\
20,000 & $74 \%$ & $78 \%$ \\
25,000 & $80 \%$ & $94 \%$ \\
\hline \hline
\end{tabular}

Table 2: Percentage of non-disabled Medicaid enrollees aged between 51 and 64 years old with assets less than the amount in the first column. Assets in the HRS are defined as total wealth net of debt. Because wealth is measured at the household level, we divide it by two for married households.

\subsection{Insurance status}

In MEPS, the question about the source of insurance coverage is asked retrospectively for each month of the year. We define a person as having employer-based insurance if he reports having ESHI for at least eight months of the year (variables PEGJA-PEGDE). The same criterion is used when defining a person as having individual insurance (variables PRIJA-PRIDE). For those few individuals who switch sources of private coverage during a year, we use the following definition of insurance status. If a person has both ESHI and individual insurance in one year and each coverage lasts for eight months or less, but the total duration of coverage lasts for more than eight months, we classify this person as individually insured. ${ }^{29}$ We classify individuals who are not covered by private insurance as publicly insured if they report having public insurance (variables PUBJAPUBDE) for at least one month. We classify individuals as publicly insured based on a shorter coverage period than private insurance because of the Medically Needy program. In the data (and in our model), an individual can be uninsured for part of the year and then enroll in Medicaid through the Medically Needy program after experiencing a large medical spending shock.

\footnotetext{
${ }^{28}$ Because the Medicaid program is administered at the state level, asset limits for categorical eligibility vary by state; some states do not have an asset test, whereas some states have a tight asset test. As of 2004, 22 states did not have an asset test for adults (Heberlein et al., 2012). Because we abstract from the state heterogeneity, our calibration strategy is to capture the overall restrictiveness of the Medicaid eligibility rules and to approximate the wealth distribution among Medicaid enrollees. Since MEPS does not contain information about assets, we use the HRS (version N), which has information about both assets and health insurance status for individuals older than 51 years old. We take the asset limit for the Medically Needy program from the data because it does not vary significantly by state.

${ }^{29}$ The results do not significantly change if we change the cutoff point to 6 or 12 months.
} 


\subsection{Medical expenditure and insurance coverage}

Medical costs in our model correspond to the total paid medical expenditures in the MEPS dataset (variable TOTEXP). These expenditures include not only out-of-pocket medical expenses but also the costs covered by insurers. In our calibration, medical expense shock is approximated by a 3-state discrete health- and age-dependent Markov process. For each age and health status, these three states correspond to the average medical expenses of the three groups: those with medical expenses below the 50th, 50th to 95 th, and above 95 th percentiles, respectively. ${ }^{30}$ To construct the transition matrix, we measure the fraction of people who move from one group to another between two consecutive years separately for people of working age (25-64) and for retirees (65 or older). ${ }^{31}$

We use MEPS to estimate the fraction of medical expenses covered by insurance policies $q\left(x_{t}, i_{t}\right)$. For retired households, we set $q_{M C R}$ to 0.5 . More details on the estimation of the medical shock process and the fraction of medical expenses covered by insurance are available in Appendix C.

\subsection{Insurance sector}

The share of health insurance premium paid by the firm $(\psi)$ is set to $80 \%$, which is in the range of empirical employer's contribution rates (Kaiser Family Foundation, 2009). We set the proportional load of insurance contracts $(\gamma)$ to 1.071. The fixed costs for an individual policy $\left(\varphi^{h}\right)$ are set to $\$ 101$ for the healthy and to $\$ 2,106$ for the unhealthy. The proportional load and fixed costs are set to match the life-cycle profile of individual insurance coverage among the healthy and the unhealthy.

\footnotetext{
${ }^{30}$ The MEPS tends to underestimate aggregate medical expenditures (Pashchenko and Porapakkarm, 2016). To bring aggregate medical expenses computed from the MEPS in line with the corresponding statistics in the National Health Expenditure Account (NHEA), the estimated medical expenses were multiplied by 1.60 for people younger than 65 years old and by 1.90 for people 65 or older. These numbers correspond to the ratio of aggregate medical spending in NHEA divided by aggregate medical spending in MEPS for people younger and older than 65 years old, respectively, averaged over the years 2002, 2004, 2006, 2008, and 2010 (the years when NHEA provides the aggregate statistics by age).

${ }^{31}$ We also tried estimating the transition matrix separately by current health status. Because the estimates are not significantly different, we pool both healthy and unhealthy groups together to get more efficient estimates. We also assume that the medical shock process of the disabled is the same as that of the non-disabled unhealthy due to the small sample size of the former group. Note that because the disabled in our model always stay unhealthy, they face higher expected medical expenses than do the non-disabled unhealthy.
} 


\subsection{ESHI offer rate}

We assume that the probability of receiving an offer of ESHI coverage is a logistic function:

$$
\operatorname{Prob}_{t}=\frac{\exp \left(u_{t}\right)}{1+\exp \left(u_{t}\right)}
$$

where the variable $u_{t}$ is an odds ratio that takes the following form:

$$
u_{t}=a_{0 t}^{E}+a_{1 t}^{E} \mathbf{1}_{\left\{h_{t-1}=0\right\}}+a_{2 t}^{E} \log \left(i n c_{t}\right)+a_{3 t}^{E} \log \left(i n c_{t}\right) \mathbf{1}_{\left\{h_{t-1}=0\right\}}+a_{4}^{E} \mathbf{1}_{\left\{g_{t-1}=1\right\}} \mathbf{1}_{\{t>25\}}
$$

Here, $a_{0 t}^{E}, a_{1 t}^{E}, a_{2 t}^{E}, a_{3 t}^{E}$ are age-dependent coefficients, and $i n c_{t}$ is individual labor income. This specification allows for a positive relationship between labor income and opportunity to be covered by ESHI, as observed in the data. We include dummy coefficients for bad health to capture the lower opportunity to access ESHI for the unhealthy.

In general, we can estimate Eq. (27) directly from the data. However, there might be a selection bias problem because people with an ESHI offer are more likely to work than are those without an ESHI offer. ${ }^{32}$ Thus, a direct estimation from the data can overstate the opportunity to receive an ESHI offer among groups with low labor force participation, such as the unhealthy. To avoid this problem, we estimate this equation inside the model together with the labor productivity process. This procedure is described in more detail in the following subsection.

\subsection{Labor productivity process}

The productivity of individuals takes the following form:

$$
z_{t}^{h}=\lambda_{t}^{h} \Upsilon_{t}=\lambda_{t}^{h} \exp \left(v_{t}\right) \exp \left(\eta_{t}\right) \exp (\xi)
$$

where $\lambda_{t}^{h}$ is the deterministic component that depends on age and health, and the stochastic component of productivity $\Upsilon_{t}$ consists of the persistent shock $v_{t}$, temporary shock $\eta_{t}$, and a fixed productivity type $\xi$ :

$$
\begin{array}{ll}
v_{t}=\rho v_{t-1}+\varepsilon_{t}, & \varepsilon_{t} \sim N\left(0, \sigma_{\varepsilon}^{2}\right) \\
\eta_{t} \sim N\left(0, \sigma_{\eta}^{2}\right) ; & \xi \sim N\left(0, \sigma_{\xi}^{2}\right)
\end{array}
$$

For the persistent shock $v_{t}$, we set $\rho$ to 0.98 and $\sigma_{\varepsilon}^{2}$ to 0.02 following the incomplete market literature (Storesletten et al., 2004; Hubbard et al., 1994; French, 2005). We set the variance of the fixed productivity type $\left(\sigma_{\xi}^{2}\right)$ to 0.242 and the variance of temporary

\footnotetext{
${ }^{32}$ See French and Jones (2011) for an investigation of the effect of employer-based health insurance on decisions to work.
} 
shock $\left(\sigma_{\eta}^{2}\right)$ to 0.057 , as in Storesletten et al. (2004). In our computation, we discretize the shock processes using 9 gridpoints for $v_{t}$ and 2 gridpoints for $\eta_{t}$ and $\xi$. The grid of $v_{t}$ is expanding over ages to capture the increasing cross-sectional variance. Because our AR(1) process is highly persistent, we use the method in Floden (2008) for our discretization. Our discretized process for $v_{t}$ generates the autocorrelation of 0.98 and the innovation variance of 0.0175 . To construct the distribution of newborn individuals, we draw $v_{1}$ in Eq. (29) from the $N\left(0,0.352^{2}\right)$ distribution following Heathcote et al. $(2010) .^{33}$

To estimate the deterministic part of productivity $\lambda_{t}^{h}$, we need to take into account the fact that in the data, we only observe labor income of workers and we do not know the potential labor income of non-workers. Given that the fraction of workers among the unhealthy is low, there can be a selection into employment. In addition, as mentioned in the previous subsection, people with an ESHI offer are more likely to work than are people without an ESHI offer. To avoid selection bias, we adapt the method developed by French (2005). We start by estimating the labor income profiles from the MEPS dataset separately for all workers and for workers without ESHI coverage. ${ }^{34}$ Then, given other parameters and equilibrium variables, we guess $\lambda_{t}^{h}$ in Eq. (28) and the coefficients $\left\{a_{0 t}^{E}, a_{1 t}^{E}, a_{2 t}^{E}, a_{3 t}^{E}, a_{4}^{E}\right\}$ in Eq. (27). Next, we feed the resulting productivity and the ESHI offer probability into our model. After solving and simulating the model, we compute the average labor income profile of all workers and workers without ESHI and the ESHI coverage profile in our model and compare them with the profiles from the data. Then, we update our guesses and reiterate until i) the labor income profiles generated by our model are the same as in the data for all workers and for workers not covered by ESHI for each health group (Figure (3) and Figure (4)); ii) the profiles of ESHI coverage in the model are the same as in the data for each health group (the low right panel of Figures (6) and $(7))$; iii) the probability of being insured by ESHI in the current period conditional on being insured by ESHI in the previous period is the same in the model and in the data. ${ }^{35}$ The advantage of this approach is that we can reconstruct the productivity and

\footnotetext{
${ }^{33}$ The parameters for the stochastic component of the productivity process that we take from other studies were estimated on a sample of working individuals. If there is a selection into employment, these estimates can be biased. We can correct this bias by estimating the underlying parameters inside our model. However, this structural estimation will be complicated by the fact that we have to solve simultaneously for a general equilibrium. Therefore, estimating $\left(\rho, \sigma_{\epsilon}^{2}, \sigma_{\eta}^{2}, \sigma_{\xi}^{2}, \sigma_{v 1}^{2}\right)$ inside the model would significantly increase our computational costs. Our approach is the same as in French (2005), and French and Jones (2011). See also Capatina (2015) for a structural estimation of these parameters in a partial equilibrium model.

${ }^{34}$ Household labor income is defined as the sum of wages (variable WAGEP) and $75 \%$ of the income from business (variable BUSNP).

${ }^{35}$ Based on our experiments, for a given set of model parameters, there seems to be a unique set of coefficients defining $\lambda_{t}^{h}$ and $u_{t}$ that can match the profiles in the data. French (2005) provides a discussion of identification of $\lambda_{t}^{h}$. The identification of $u_{t}$ is straightforward, given that the ESHI take-up rate is $96 \%$ in the data (and $99 \%$ in our model). The coefficients $a_{0 t}^{E}, a_{1 t}^{E}, a_{2 t}^{E}$ and $a_{3 t}^{E}$ are pinned down by the
} 
the opportunity to access ESHI for individuals whom we do not observe working in the data, most of whom are Medicaid enrollees.
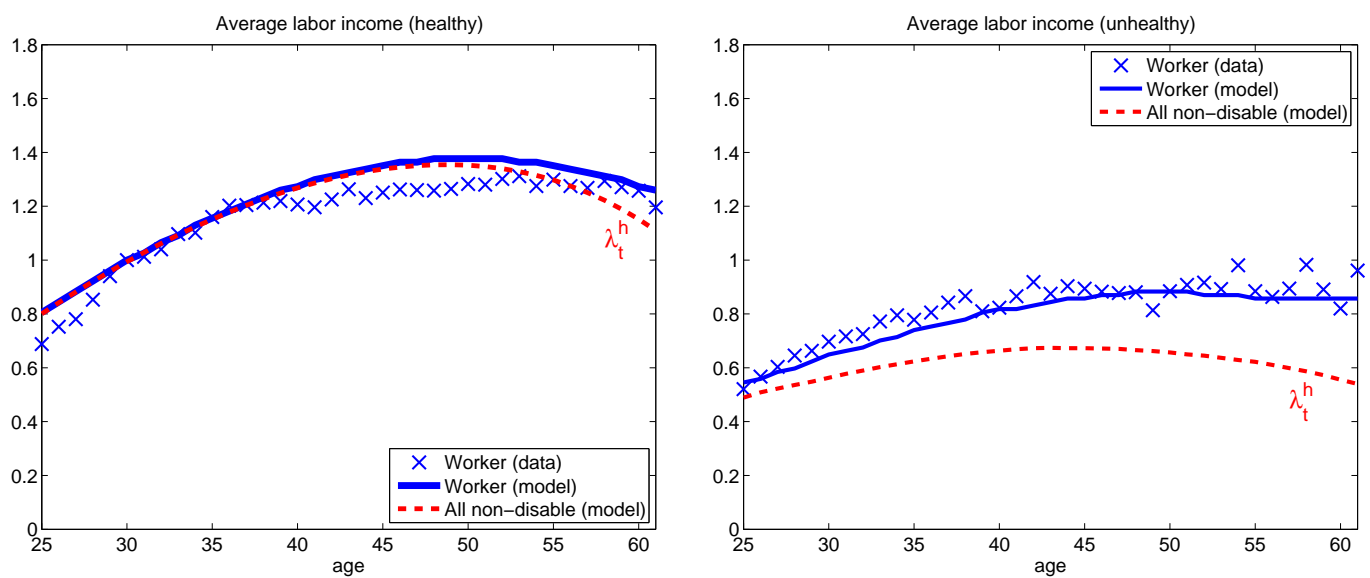

Figure 3: Average labor income of workers (data and model), and of everyone (model). The latter profile takes into account the unobserved productivity of those people who do not work. The average income of the healthy at age 30 is normalized to one.
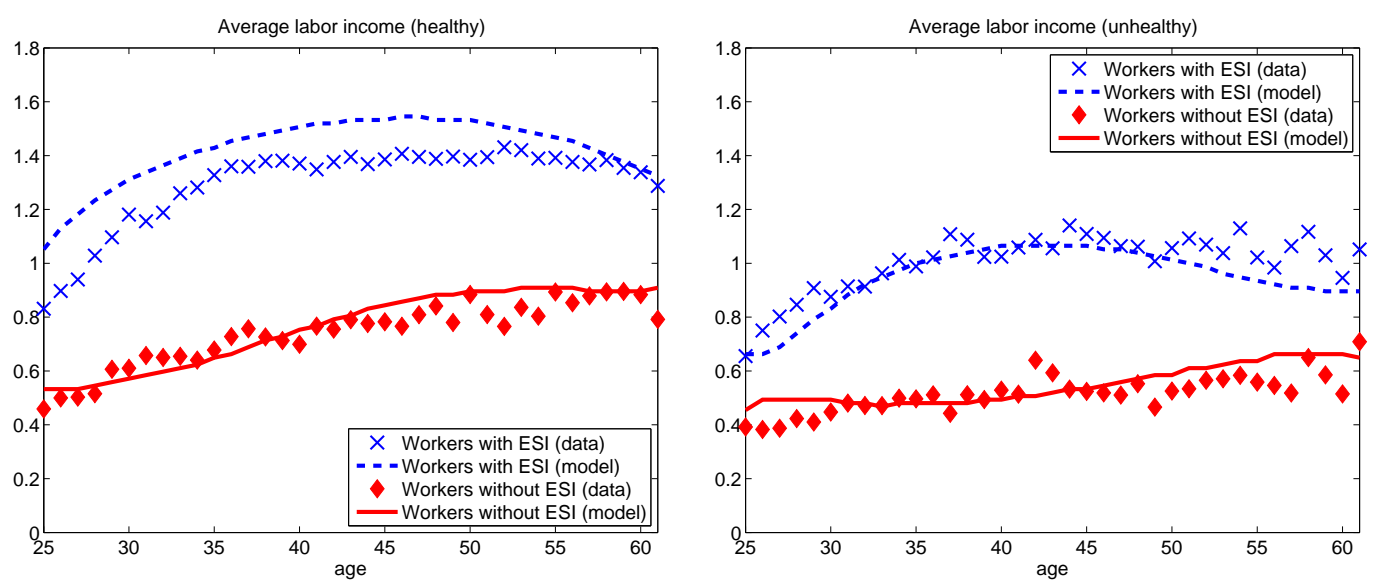

Figure 4: Average labor income of workers with and without ESHI coverage (data and model). The average income of the healthy at age 30 is normalized to one.

Figure (3) plots the labor income profiles of workers observed in the data and simulated by the model and compares them with the average potential labor income computed for all non-disabled individuals in the model (dashed lines). ${ }^{36}$ The latter profile takes into account the unobserved productivity of those people who do not work. The average labor income of workers is higher than the average labor income that includes potential

profiles of ESHI coverage; the labor income profiles of workers without ESHI, $a_{4}^{E}$, is used to match the persistence of ESHI coverage.

${ }^{36}$ To obtain the age profile of labor income among workers (and workers without ESHI) in Figures (3) and (4), we regress the labor income of workers (and workers without ESHI) on dummy variables of age and year separately for the healthy and for the unhealthy. The average labor income of each age is the resulting coefficient on the dummy variable of the corresponding age. 
income of non-workers because people with low productivity tend to drop out from the employment pool. Our estimates also show that unhealthy people are inherently less productive.

Figure (4) compares the average labor income among workers with and without ESHI coverage by health. Our model can capture well the empirical fact that workers who are not covered by ESHI have significantly lower income than do those who have ESHI coverage. Note that in our calibration, we target the average income among workers without ESHI. However, our model can still capture well the average income among workers with ESHI, particularly the unhealthy group. In addition, our calibration strategy captures the positive effect of the availability of ESHI on the probability to work, which is especially strong among low-income unhealthy individuals. In particular, among unhealthy workers with labor income below $400 \%$ of FPL, $56 \%$ receive an ESHI offer. In contrast, among unhealthy non-workers with potential labor income below $400 \%$ of FPL, only $15 \%$ would receive an ESHI offer if they choose to work. This difference in probability of receiving an ESHI offer is significantly smaller for the healthy; the corresponding numbers are $57 \%$ for workers and $52 \%$ for non-workers. ${ }^{37}$

The model parametrization is summarized in Table 11 in Appendix A.

\section{Baseline model performance}

Tables 3 and 4 show how the fraction of workers and the aggregate health insurance statistics among non-disabled individuals aged 25-61 years old produced by our model compare to the data. Our model closely tracks all of the aggregate statistics, including the fraction of the unhealthy in different insurance categories. In addition, our calibration strategy allows the model to match the targeted age profiles of employment by health (left panel of Figure (5)) and the targeted insurance coverage by health (Figures (6)-(7)).

The right panel of Figure (5) shows the fraction of workers among people with and without Medicaid coverage. In addition, the last two rows of Table 3 report the fraction of workers among Medicaid enrollees by health status. Note that we do not target these statistics in our calibration, but our model can still replicate these moments.

Our quantitative analysis in the next section depends on the extensive margin elasticity of labor supply in our model. To calculate the elasticity, we compute the percentage change in the fraction of workers in response to a one percent permanent increase in

\footnotetext{
${ }^{37}$ There is no difference in the probability to receive an ESHI offer between workers and non-workers with income (potential income) above $400 \%$ of FPL (for both the healthy and the unhealthy).
} 


\begin{tabular}{lcc}
\hline \hline & Data & Baseline model \\
\hline $\begin{array}{l}\text { By health status } \\
\text { all }\end{array}$ & 91.5 & 94.8 \\
$\quad$ healthy & 94.1 & 98.4 \\
$\quad$ unhealthy & 79.8 & 78.5 \\
By insurance & & \\
$\quad$ w/o Medicaid & & \\
with Medicaid & 93.8 & 97.8 \\
$\quad$ - healthy & 51.6 & 51.2 \\
$\quad$ - unhealthy & 61.2 & 76.1 \\
\hline \hline
\end{tabular}

Table 3: Fraction of workers among non-disabled individuals aged 25-61 (data vs baseline model)

\begin{tabular}{|c|c|c|c|c|c|c|c|c|}
\hline & \multicolumn{4}{|c|}{ Data } & \multicolumn{4}{|c|}{ Baseline model } \\
\hline & ESHI & individual & uninsured & public & ESHI & individual & uninsured & public \\
\hline all & 63.3 & 4.7 & 26.2 & 5.7 & 63.4 & 5.4 & 24.9 & 6.3 \\
\hline healthy & 66.9 & 5.0 & 24.1 & 4.0 & 66.9 & 5.9 & 23.7 & 3.5 \\
\hline unhealthy & 47.7 & 3.5 & 35.2 & 13.6 & 47.2 & 3.1 & 30.5 & 19.2 \\
\hline$\%$ unhealthy by insurance & 13.7 & 13.2 & 24.5 & 43.2 & 13.2 & 10.2 & 21.7 & 54.5 \\
\hline
\end{tabular}

Table 4: Insurance coverage among non-disabled individuals aged 25-61 (data vs baseline model)

labor productivity in the partial equilibrium. The resulting extensive margin elasticity is 0.17 for the entire working-age population; the elasticity among the unhealthy (0.46) is higher than that of the healthy (0.12). Our elasticities are in line with estimates in the empirical literature; quasi-experimental studies usually find that elasticities for different subgroups of the population lie within the range of $0.13-0.43$, and elasticities are higher for groups who are less attached to the labor force. ${ }^{38}$

\section{Results}

\subsection{Characteristics of non-working Medicaid beneficiaries}

To understand if the Medicaid program significantly distorts labor supply decisions, we start by analyzing the productivity of those Medicaid enrollees who do not work. Using our estimates of the unobserved productivity among non-workers, we can measure the fraction of Medicaid beneficiaries whose potential labor income is above the income test limit. The second row of Table 5 shows that $25.3 \%$ of all Medicaid beneficiaries have potential income above the income test limit and thus will lose eligibility if they start working. An important observation is that the fraction of people whose potential

\footnotetext{
${ }^{38}$ See Chetty et al. (2012) for an extensive review and discussion about the empirical estimates of the extensive margin elasticity.
} 

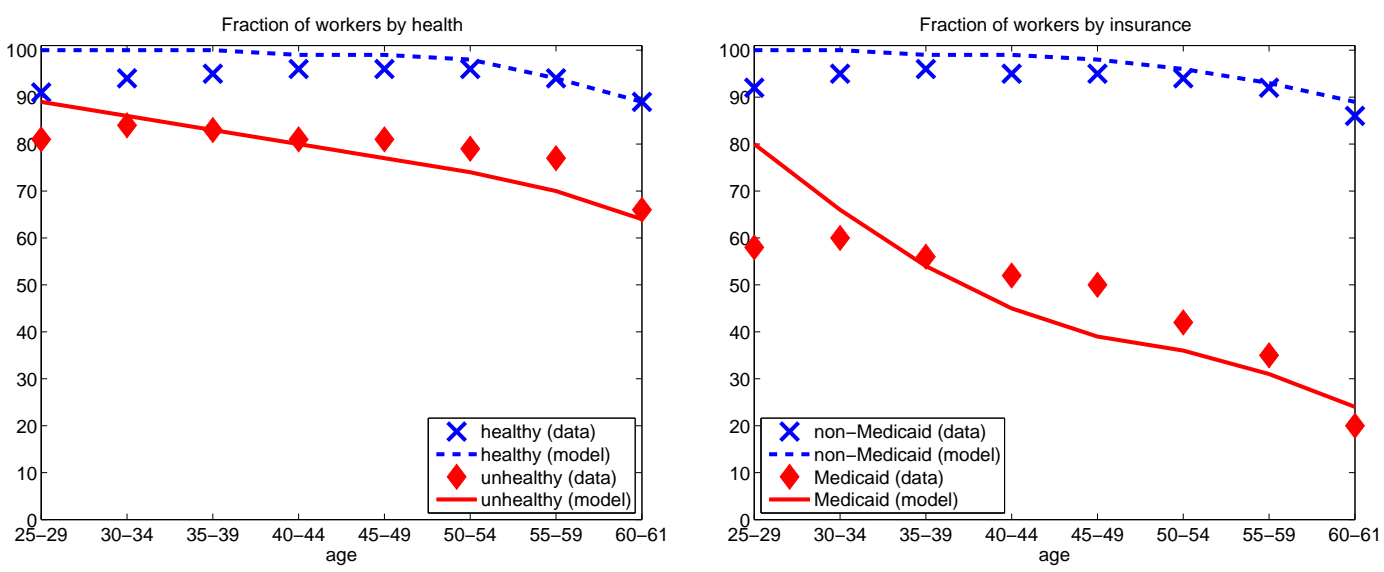

Figure 5: Employment profiles among non-disabled individuals (data vs baseline model). Left panel: employment by health. Right panel: employment for individuals with and without Medicaid coverage.

income is above the income test limit is noticeably higher among the unhealthy $(36.4 \%$ compared with $12.2 \%$ for the healthy).

\begin{tabular}{lccc}
\hline \hline & \% of all enrollees & \% of healthy enrollees & \% of unhealthy enrollees \\
\hline $\begin{array}{l}\text { non-workers (baseline) } \\
\text { enrollees with potential }\end{array}$ & 51.9 & 28.5 & 71.8 \\
$\begin{array}{l}\text { income }>\text { income test } \\
\text { limit }\end{array}$ & 25.3 & 12.2 & 36.4 \\
$\begin{array}{l}\text { non-workers } \Rightarrow \text { workers } \\
\text { if not losing eligibility }\end{array}$ & 22.9 & & 32.9 \\
\hline \hline
\end{tabular}

Table 5: Decomposition of Medicaid beneficiaries (non-disabled, age 25-64)

Given that a substantial fraction of Medicaid beneficiaries will lose eligibility if they work, an important question is whether Medicaid actually induced them to stop working. To understand to what extent the decision not to work of people with relatively high productivity is affected by Medicaid, we run the following experiment. We consider a partial equilibrium environment where we allow people who are currently on Medicaid to keep their eligibility for one period regardless of their income. In other words, people who are enrolled in Medicaid in the baseline economy become "vested" for one period; they cannot lose their eligibility even when their income exceeds the income test. The change in the labor supply behavior of Medicaid enrollees in this experiment allows us to evaluate to what extent the possibility of losing Medicaid eligibility affects their decisions in the baseline case. The last row of Table 5 shows that $22.9 \%$ of all Medicaid enrollees will choose to work in this experiment.

To understand better the difference between Medicaid beneficiaries who stop working to gain eligibility and the other Medicaid beneficiaries, Table 6 compares their medical expenses, potential labor income and assets. The average medical expenses of people who 

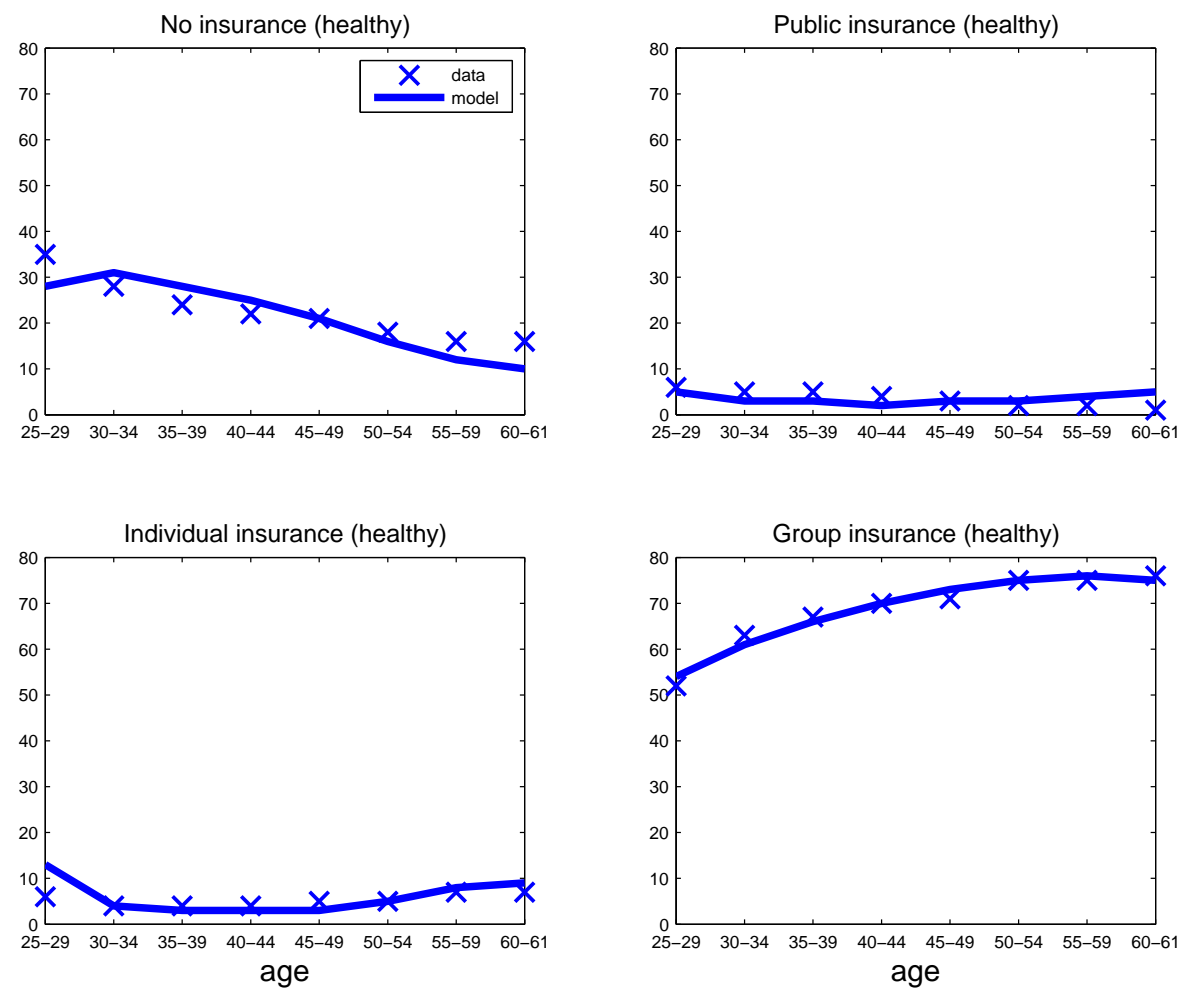

Figure 6: Insurance status among healthy non-disabled individuals (data vs baseline model)
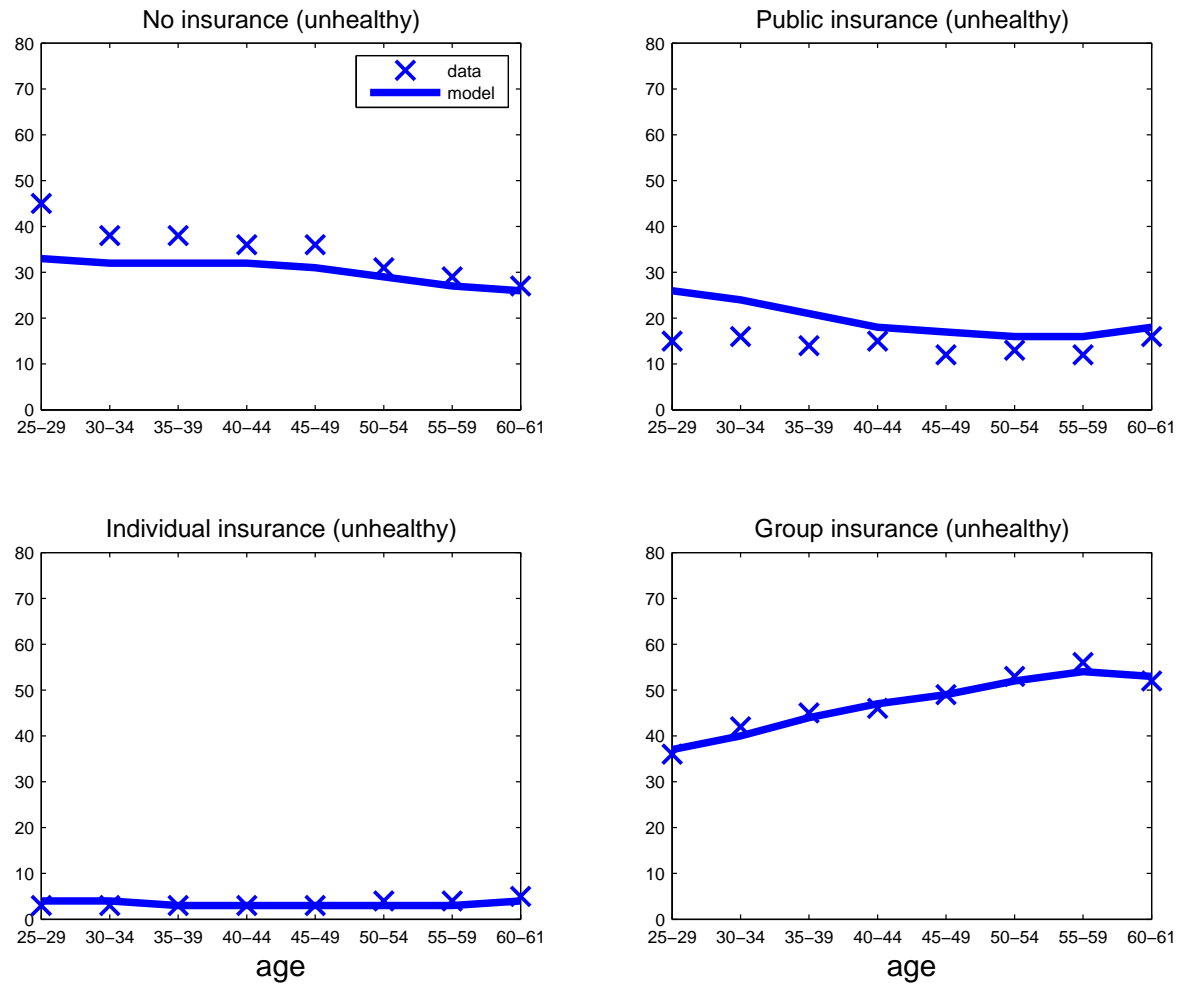

Figure 7: Insurance status among unhealthy non-disabled individuals (data vs baseline model) 
choose not to work to become eligible for Medicaid are noticeably higher than the average medical expenses of the rest of Medicaid beneficiaries $(\$ 7,926$ vs $\$ 6,359)$. At the same time, the former group is significantly more productive; their potential labor income is around $50 \%$ higher than the potential labor income of the latter group. Importantly, the group of beneficiaries who do not work to meet the eligibility criteria, on average, holds significantly more assets than the rest of Medicaid beneficiaries $(\$ 14,229$ vs $\$ 2,790)$. As a result, the former group is better self-insured; the average share of their medical expenses in total potential resources (assets plus potential labor income) is significantly lower than this share for the rest of Medicaid beneficiaries (32.9\% vs $71.4 \%$ ). To summarize, Medicaid beneficiaries who do not work to obtain access to public insurance are mostly unhealthy people with high medical expenses but with relatively high potential labor income and more assets compared with other Medicaid enrollees.

\begin{tabular}{lcccc}
\hline \hline & medical expenses & potential earning & asset & $\frac{\text { medical expense }}{\text { potential cash-on-hand }}$ \\
\hline $\begin{array}{l}\text { non-workers } \Rightarrow \quad \text { workers if } \\
\text { not losing eligibility }\end{array}$ & $\$ 7,926$ & $\$ 9,871$ & $\$ 14,229$ & $32.9 \%$ \\
other Medicaid beneficiaries & $\$ 6,359$ & $\$ 6,116$ & $\$ 2,790$ & $71.4 \%$ \\
\hline all Medicaid & $\$ 6,719$ & $\$ 7,217$ & $\$ 5,415$ & $53.2 \%$ \\
\hline \hline
\end{tabular}

Table 6: Medicaid enrollees who would work if they could keep Medicaid eligibility vs other enrollees (non-disabled, age 25-64)

\subsection{Welfare effects}

The previous section shows that Medicaid substantially distorts labor supply decisions, particulary among unhealthy people. These distortions can negatively affect welfare for several reasons. First, some people with relatively high productivity do not work. Second, some people receiving public transfers have good opportunities to self-insure. At the same time, the size of public transfers received by this group is large because of their high medical expenses. This section evaluates the welfare costs of these distortions. An important observation is that the labor supply distortions happen because Medicaid eligibility depends on labor income which is endogenous. People who want to obtain public insurance but whose labor income is too high have the option to stop working. This type of behavior (moral hazard) can be eliminated if Medicaid eligibility is based on exogenous productivity. Thus, to evaluate the welfare effects of the distortions, we assume that productivity is observable and modify the Medicaid eligibility as follows:

$$
\begin{array}{lll}
k_{t} r+\widetilde{w} z_{t}^{h} \bar{l} \leq y^{c a t} & \text { and } k_{t} \leq k^{c a t} & \text { for categorical eligibility, } \\
k_{t} r+\widetilde{w} z_{t}^{h} \bar{l}-x_{t}^{h} \leq y^{M N} & \text { and } k_{t} \leq k^{M N} & \text { for the Medically Needy program. }
\end{array}
$$


Thus, Medicaid eligibility depends on the potential labor income of an individual but not on his current labor income (i.e., there is no private information). In other words, even when an individual has zero labor income because he does not work, he will not be eligible if his productivity allows him to earn more than the income test limit. To be consistent, we also set eligibility for the Medically Needy program based on the potential labor income. We refer to this experiment as the observable productivity case and it will be a benchmark for our policy discussions in the next section.

To evaluate welfare effects from implementing this new eligibility criterion, we maintain the total budget of the government transfers as in the baseline. To do this, we adjust the income eligibility thresholds $y^{\text {cat }}$ and $y^{M N}$ until the total spending on Medicaid and the minimum consumption guarantee for the working-age population in the experimental case is the same as in the baseline economy. This way our welfare analysis measures welfare effects from removing distortions and reallocating the fixed public transfers rather than changing the size of the redistribution in the economy. ${ }^{39}$

\begin{tabular}{lcc}
\hline \hline & Baseline & $\begin{array}{c}\text { Observable } \\
\text { productivity }\end{array}$ \\
\hline Income test: $y^{c a t}, y^{M N}(\% \mathrm{FPL})$ & $70.5 \%$ & $96.8 \%$ \\
Income tax: $\tau_{y}$ & $6.66 \%$ & $6.43 \%$ \\
& & \\
\% Employment rate (non-disable, aged & $25-64)$ & \\
- all & 93.9 & 95.4 \\
- healthy & 97.7 & 98.2 \\
- unhealthy & 76.9 & 82.7 \\
& & \\
$\% \Delta$ aggregate labor productivity & - & 0.40 \\
$\% \Delta$ aggregate capital & - & 0.84 \\
$\% \Delta$ aggregate output & - & 0.55 \\
Ex-ante consumption equivalent $(\%)$ & - & 1.17 \\
\hline \hline
\end{tabular}

Table 7: The effects of removing Medicaid distortions on the labor supply

Tables 7 and 8 compare an economy where eligibility is based on productivity with the baseline economy. After implementing the new eligibility criteria, non-workers with relatively high potential labor income can no longer enroll in the Medicaid program. Given that many of these people have relatively high medical expenses, this significantly

\footnotetext{
${ }^{39}$ Since households change their labor supply and saving decisions, we also slightly adjust the proportional income tax $\tau_{y}$ to balance the government budget. In Appendix D, we consider an alternative setup where, instead of adjusting the income eligibility threshold to maintain the size of the public transfer programs, we only adjust $\tau_{y}$ to balance the government budget. The qualitative conclusions in this case stay the same.
} 


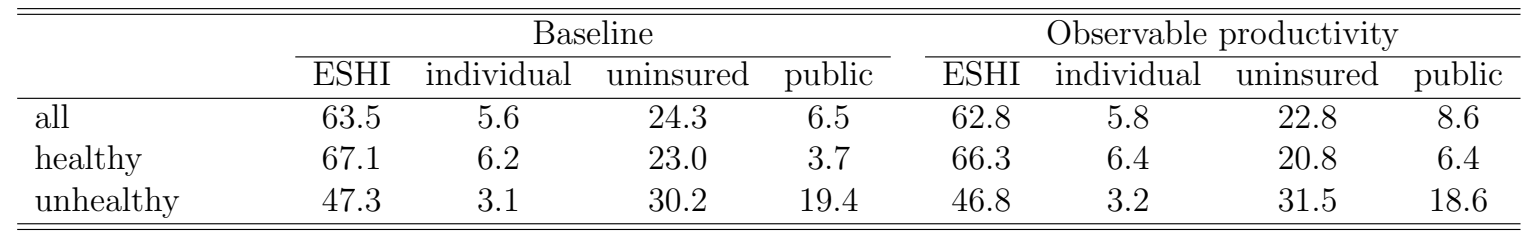

Table 8: The effects of removing Medicaid distortions on the labor supply: change in insurance coverage (non-disabled, age 25-64)

decreases Medicaid spending. To maintain the same level of public transfers, this freedup budget is used to cover more people with truly low productivity; the income test limit increases from $70.5 \%$ to $96.8 \%$ of FPL, and the percentage of people enrolled in Medicaid increases from $6.5 \%$ to $8.6 \%$.

To measure welfare in this experiment, we use an ex-ante consumption equivalence that captures long-run welfare gains. ${ }^{40}$ Eliminating the labor supply distortions results in sizeable welfare gains; a newborn individual in the baseline economy is willing to give up $1.17 \%$ of his annual consumption every period to be born in the economy where productivity is observable. Note that the increase in labor supply has only a marginal contribution to these welfare gains. Although employment among the unhealthy increases from $76.9 \%$ to $82.7 \%$, the aggregate labor productivity, aggregate employment, aggregate output and capital increase only slightly. Most of the welfare gains come from the more efficient use of Medicaid spending. As shown in the previous subsection, people who lose eligibility if their potential labor income is observable are relatively well self-insured due to high earning capacity and the ability to accumulate relatively high assets. On the other hand, the new enrollees have fewer opportunities to self-insure, and private insurance premiums and medical costs constitute a large fraction of their resources. Thus, reallocating public transfers from the former group to the latter improves welfare. ${ }^{41}$

\footnotetext{
${ }^{40}$ The ex-ante welfare criterion is commonly used in the NDPF literature. Let $V^{B}$ and $V^{E}$ denote the value function of a newborn in the baseline and the experimental economy, respectively. The welfare gains $x$ can be defined as

$$
x=100 *\left[1-\left(\frac{V^{B}}{V^{E}}\right)^{\frac{1}{\chi(1-\sigma)}}\right]
$$

The resulting number represents the percentage of annual consumption a newborn in the experimental economy is willing to give up to be indifferent between the baseline and experimental economies. The positive number implies welfare gains.

${ }^{41}$ In Appendix D, we show that in the alternative setup, when we only adjust $\tau_{y}$, the welfare gains are equal to $0.18 \%$ of annual consumption. The gains are smaller because the savings from withdrawing public transfers from people with high potential income are allocated to the whole population in terms of reduced taxes as opposed to the relatively poor people in the benchmark case.
} 


\section{Policy discussion}

The previous section shows that if productivity is observable, Medicaid can provide insurance to people with truly low productivity without distorting work incentives and that this can substantially improve welfare. An important question is how to improve the trade-off between insurance and incentives in an environment where productivity is unobservable. The efficient provision of insurance in dynamic economies with private information has been extensively studied by the New Dynamic Public Finance literature. One important result from this literature is that to correct the incentive problem when stochastic productivity is unobservable, saving decisions should be distorted. Golosov and Tsyvinski (2006) show that in the case of disability insurance, the optimal wedge on savings can be achieved by asset testing. The intuition behind this result is that individuals who falsely claim disability accumulate assets beforehand to smooth their consumption when not working and receiving disability transfers. Asset testing makes this strategy unattractive because able individuals with low assets are better off by working. Medicaid has an insurance-incentives trade-off similar to disability insurance. It provides transfers to low-income people, but it cannot separate truly low-productive individuals from nonworkers with high productivity. In this section, we explore whether asset testing can be an efficient tool to correct incentives in the case of the Medicaid program.

We start by investigating the effects of changing the existing asset limit in Section 7.1. We show that asset testing creates a trade-off between lower distortions on the labor supply and higher saving distortions, which does not allow it to achieve the same welfare gains as the benchmark case of observable productivity. In Section 7.2, we take this analysis one step further by exploring the possibility of using different asset limits for workers and non-workers. We show that this policy is as effective in reducing labor supply distortions as is uniform asset testing, but it does not create unnecessary saving distortions. As a result, the welfare gains of this policy are almost equivalent to the benchmark case of observable productivity. ${ }^{42}$

\footnotetext{
${ }^{42}$ We assume that an asset test is perfectly enforceable, i.e., individuals cannot hide their assets. Although in theory, it is possible to hide some assets from the Medicaid program's administrators, there is evidence that asset tests are enforced. Gruber and Yelowitz (1999) examine the expansion of the Medicaid program over the 1984-1993 period and show that public insurance crowds out private savings and that this effect is much stronger in the presence of an asset test. Sullivan (2006) finds a sizeable effect of eliminating vehicles from countable assets when determining eligibility for welfare or increasing vehicle exemption limits on vehicle ownership. Ganong and Liebman (2013) calculated that the removing asset test from the food stamps program in the 2000s increases enrollment of people with assets above the previously existing limit by 560,000. Importantly, if we assume that in our baseline economy, an asset test is not enforceable, we can show that the welfare gains of tightening the asset limit are even larger, making a stronger case for using and enforcing an asset test in means-tested programs as an important policy implication.
} 


\section{1 (Uniform) Asset testing}

To understand the role of asset testing in reducing labor supply distortions, we start by considering the effects of removing asset testing in two economies: i) with unobservable productivity, and ii) with observable productivity. In other words, in the first economy, eligibility for Medicaid is determined according to the following rule:

$$
\begin{aligned}
& k_{t} r+\widetilde{w} z_{t}^{h} l_{t} \leq y^{\text {cat }} \quad \text { for categorical eligibility, } \\
& k_{t} r+\widetilde{w} z_{t}^{h} l_{t}-x_{t}^{h} \leq y^{M N} \text { and } k_{t} \leq k^{M N} \text { for the Medically Needy program; }
\end{aligned}
$$

while in the second economy, the eligibility criteria looks as follows:

$$
\begin{aligned}
& k_{t} r+\widetilde{w} z_{t}^{h} \bar{l} \leq y^{c a t} \quad \text { for categorical eligibility, } \\
& k_{t} r+\widetilde{w} z_{t}^{h} \bar{l}-x_{t}^{h} \leq y^{M N} \text { and } k_{t} \leq k^{M N} \text { for the Medically Needy program. }
\end{aligned}
$$

In both cases, we keep the asset test for the Medically Needy program as in the baseline to maintain the role of this program as ex-post insurance for impoverished people with no resources to pay for their medical costs. As in the previous section, we fix the welfare

\begin{tabular}{|c|c|c|c|c|c|c|c|c|}
\hline \multirow{2}{*}{ Asset test $\left(k^{C A T}\right)$} & \multirow{2}{*}{$\begin{array}{c}\text { Income test } \\
(\% F P L)\end{array}$} & \multirow{2}{*}{$\begin{array}{l}\text { CEV } \\
(\%)\end{array}$} & \multicolumn{2}{|c|}{ Employment (\%) } & \multicolumn{4}{|c|}{ Insurance (\%) } \\
\hline & & & unhealthy & healthy & unins & pub & ind & ESHI \\
\hline \multicolumn{9}{|c|}{ Productivity is observed } \\
\hline 1. No asset test & 93.2 & 1.41 & 82.3 & 98.1 & 23.3 & 8.3 & 5.6 & 62.8 \\
\hline $\begin{array}{l}\text { 2. } \$ 26,000 \text { (bench- } \\
\text { mark) }\end{array}$ & 96.7 & 1.17 & 82.7 & 98.2 & 22.8 & 8.6 & 5.8 & 62.8 \\
\hline \multicolumn{9}{|c|}{ Productivity is unobserved } \\
\hline 3. No asset test & 11.7 & -0.12 & 75.0 & 97.4 & 24.6 & 6.3 & 5.6 & 63.5 \\
\hline 4. $\$ 26,000$ (baseline) & 70.5 & - & 76.9 & 97.7 & 24.3 & 6.5 & 5.6 & 63.5 \\
\hline 5. $\$ 23,000$ & 84.7 & 0.46 & 79.2 & 98.0 & 23.4 & 7.5 & 5.8 & 63.3 \\
\hline 6. $\$ 20,000$ & 89.4 & 0.64 & 80.1 & 98.0 & 23.1 & 7.9 & 5.8 & 63.2 \\
\hline 7. $\$ 15,000$ & 93.7 & 0.67 & 80.8 & 98.1 & 22.8 & 8.2 & 6.0 & 63.0 \\
\hline 8. $\$ 10,000$ & 97.8 & 0.69 & 81.4 & 98.2 & 22.2 & 8.4 & 6.4 & 63.0 \\
\hline 8. $\$ 5,000$ & 105.8 & 0.64 & 82.3 & 98.2 & 21.9 & 8.8 & 6.5 & 62.9 \\
\hline 9. $\$ 2,000$ & 108.1 & 0.45 & 81.9 & 98.1 & 22.9 & 8.4 & 5.7 & 63.1 \\
\hline
\end{tabular}
budget by adjusting the income test $\left(y^{c a t}\right.$ and $\left.y^{M N}\right)$. The results of these experiments are reported in Rows 1 and 2 of Table 9 for the economy with observable productivity and in Rows 3 and 4 for the economy where productivity is unobservable.

Table 9: Effects of (uniform) asset testing (non-disabled, age 25-64)

Removing asset testing has very different effects depending on whether productivity is observable. In an economy where productivity is observable, removing asset testing increases welfare gains from $1.17 \%$ (our benchmark full information economy) to $1.41 \%$. This happens because asset testing creates distortions on saving decisions that are not 
needed when there is no private information. In contrast, if productivity is unobservable, eliminating asset testing leads to welfare losses equivalent to $-0.12 \%$ of the annual consumption. This happens because the distortions on the labor supply created by Medicaid become more severe. More people with relatively high productivity and high medical costs, who previously could not enroll in Medicaid because of their high assets, now stop working and become eligible for the program. Given their high medical expenses, this increases the spending of the Medicaid program. To keep the welfare budget fixed as in the baseline economy, the income eligibility threshold has to be decreased from $70.5 \%$ to $11.7 \%$ of FPL. The fraction of beneficiaries who would start working if they can keep eligibility increases to $31 \%$ (from $22.9 \%$ in the baseline economy). This experiment illustrates the important role that asset testing plays in preventing people who have relatively high productivity and are well self-insured from obtaining free public insurance by changing their labor supply.

In the next set of experiments, we gradually decrease the asset limit in the baseline economy from $\$ 26,000$ to $\$ 2,000$ to understand whether this can reduce the labor supply distortions and move the economy closer to the benchmark case of observable productivity. As before, in each experiment, we fix the size of the welfare budget by adjusting the income eligibility threshold for Medicaid $\left(y^{c a t}, y^{M N}\right)$. The left panel of Figure (8) shows that lowering the asset limit from $\$ 26,000$ (baseline level) to $\$ 2,000$ almost completely eliminates the moral hazard problem; the percentage of Medicaid enrollees who choose not to work to obtain eligibility drops to around $1 \%$ (solid line). Rows 5 to 9 of Table 9 show the effects of the tighter asset testing on employment and insurance statistics. The employment rate among the unhealthy increases from $76.9 \%$ to $81.9 \%$, which is closer to the benchmark economy where productivity is observable (82.7\%). However, although in terms of employment, the economy with a $\$ 2,000$ asset limit is close to the benchmark economy with observable productivity, it brings significantly lower welfare gains; $0.45 \%$ of the annual consumption compared with $1.17 \%$ in the benchmark economy (second row of Table 9). This is because the positive effect of eliminating labor supply distortions is partially offset by the negative effect of large saving distortions created by the tight asset test: many low-income people accumulate fewer assets to meet the eligibility requirements. The solid line in the right panel of Figure (8) shows that the percentage of people aged 25-64 with assets below $\$ 2,000$ increases from around $14 \%$ in the baseline economy to almost $17 \%$ in the economy with a very tight asset test. ${ }^{43}$

The trade-off between labor supply and saving distortions results in non-linear welfare changes when tightening asset testing, as shown in the left panel of Figure (9) for a newborn individual (solid line) and in the right panel of Figure (9) for a 25-year-old

\footnotetext{
${ }^{43}$ Gruber and Yelowitz (1999) also find that asset testing has a sizeable negative effect on savings of Medicaid enrollees.
} 

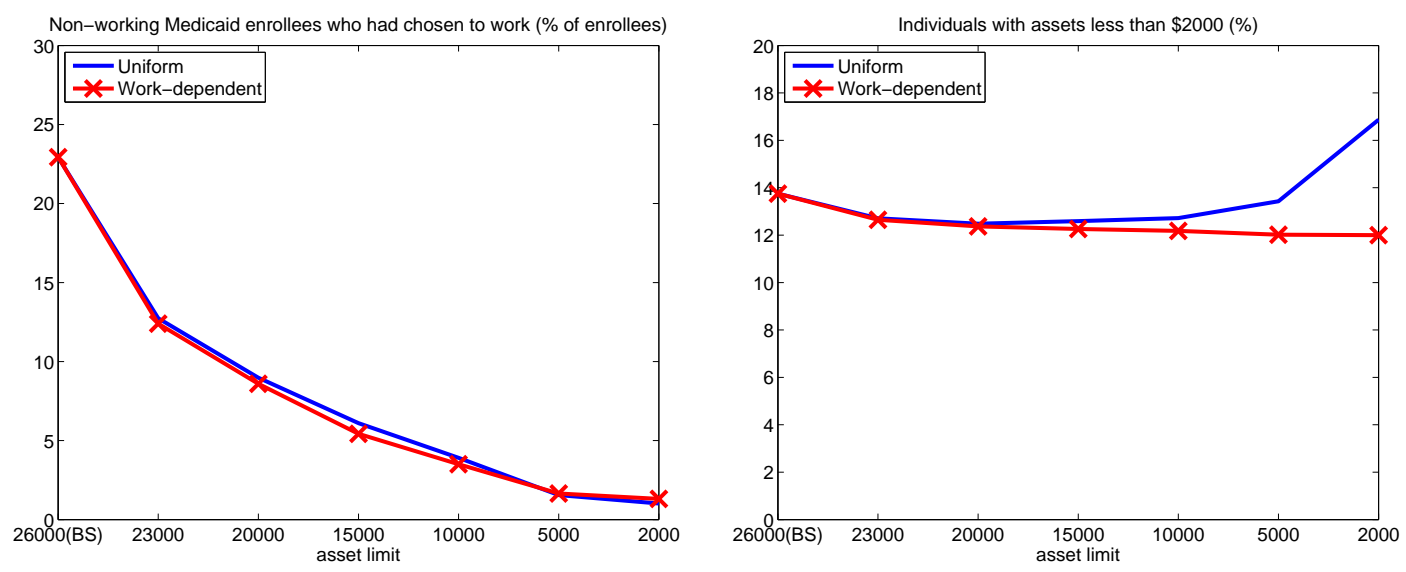

Figure 8: Labor supply distortions vs saving distortions. Left panel: non-working beneficiaries who would choose to work if allowed to keep Medicaid eligibility (\% of all enrollees). Right panel: the percentage of individuals with assets below $\$ 2,000$ (\% of all individuals between ages 25 and 64 ). Solid line: uniform asset testing; crossed line: work-dependent asset testing
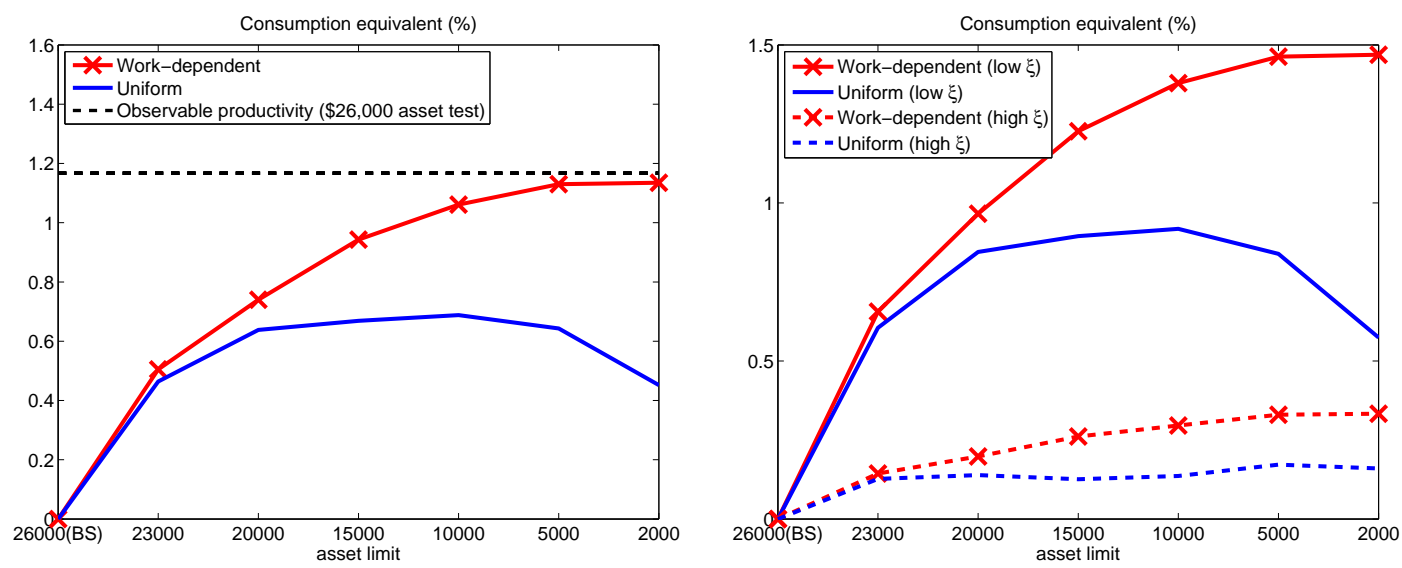

Figure 9: Welfare effects of asset testing. Left panel: the ex-ante CEV of a person aged 25. Right panel: the CEV of a person aged 25 after realizing the fixed productivity type $(\xi)$. The lines without crosses are for uniform asset testing, and those with crosses are for work-dependent asset testing.

individual with a low (high) fixed productivity type (solid and dashed lines for low and high type, respectively). Notice that the non-linear pattern of welfare gains is more pronounced among people with low fixed productivity. Since people in this group are more likely to rely on public health insurance, their saving decisions are more affected by asset testing. Note that in this set of experiments, the highest ex-ante welfare is achieved if asset limit is equal to $\$ 10,000$. In this case, the distortions on the labor supply are less compared with the baseline case, and the distortions on saving decisions are less than in the case of a $\$ 2,000$ asset limit. As a result, the welfare gains are higher than in both the baseline and in the $\$ 2,000$ asset limit economy (0.69\% of the annual consumption) but are still significantly smaller than in the case of observable productivity. 


\subsection{Work-dependent asset testing}

The previous section shows that strict asset testing can almost entirely eliminate distortions on the labor supply of Medicaid beneficiaries but at a cost of substantially distorting saving decisions. In this section, we consider a more flexible asset testing policy that allows asset limits to depend on labor supply decisions. The rationale for this policy is based on the finding in the NDPF literature that one way to reduce the adverse effect of savings on work incentives is to introduce income-dependent wealth taxes (Kocherlakota, 2005, Albanesi and Sleet, 2006). The intuition here is as follows. Highly productive individuals can always mimic low productive individuals by working less. The attractiveness of this strategy increases with asset holding since wealth can substitute for forgone labor income. To make this behavior less attractive, an individual who reports low income should face higher marginal taxes on wealth. In our case, individuals with high and low productivity are observationally identical only when they do not work. Thus, asset testing (which is equivalent to a wealth tax) should be stricter for non-workers. In the next set of experiments, we allow asset limits to be different for working and nonworking Medicaid enrollees. ${ }^{44}$ Table 10 shows how policies that tighten the asset limit for non-workers from $\$ 26,000$ (baseline) to $\$ 2,000$, while keeping the asset limit for workers unchanged at the baseline level, affect employment and insurance. The crossed line in the left panel of Figure (8) shows that stricter asset testing for non-workers is effective in reducing moral hazard behavior among Medicaid beneficiaries; when the asset limit is set to $\$ 2,000$, only around $1 \%$ of enrollees would choose to work if they could keep their eligibility. The crossed line in the left panel of Figure (9) shows that tightening the asset limit for non-workers increases welfare, and when the asset limit is set to $\$ 2,000$, welfare gains approach the level of the full information benchmark $(1.13 \%$ compared to $1.17 \%$ in the latter case). ${ }^{45}$ As shown by the crossed line in the right panel of Figure (8), in contrast to uniform asset testing, work-dependent asset testing does not create significant saving distortions. With the asset limit at $\$ 2,000$, the percentage of people aged 25 to 64 years old with assets below $\$ 2,000$ is $12 \%$, which is the same as in the benchmark economy with observable productivity and significantly lower compared with the economy with a $\$ 2,000$ asset limit for both workers and non-workers $(17 \%)$. Thus, by allowing working and non-working Medicaid enrollees to face different asset limits, we can achieve almost the same outcome as in the "ideal" case of linking Medicaid eligibility to unobservable productivity.

\footnotetext{
${ }^{44}$ In Appendix F, we discuss how a work-dependent asset testing policy would look like if individuals were allowed to adjust their labor supply along the intensive margin.

${ }^{45}$ In Appendix E, we show that completely removing asset testing of workers results in welfare gains that are slightly higher and close to the welfare gains in the economy with observable productivity and no asset testing.
} 


\begin{tabular}{|c|c|c|c|c|c|c|c|c|}
\hline \multirow{2}{*}{$\begin{array}{l}\text { Asset test }\left(k^{C A T}\right) \\
\text { for non-workers }\end{array}$} & \multirow{2}{*}{$\begin{array}{c}\text { Income Test } \\
(\% F P L)\end{array}$} & \multirow{2}{*}{$\begin{array}{l}\text { CEV } \\
(\%)\end{array}$} & \multicolumn{2}{|c|}{ employment (\%) } & \multicolumn{4}{|c|}{ insurance (\%) } \\
\hline & & & unhealthy & healthy & unins & pub & Ind & ESHI \\
\hline 1. $\$ 26,000$ (baseline) & 70.5 & - & 76.9 & 97.7 & 24.3 & 6.5 & 5.6 & 63.5 \\
\hline 2. $\$ 23,000$ & 84.9 & 0.505 & 79.5 & 98.0 & 23.4 & 7.6 & 5.8 & 63.2 \\
\hline 3. $\$ 20,000$ & 89.3 & 0.740 & 80.8 & 98.1 & 23.2 & 8.0 & 5.8 & 63.1 \\
\hline 4. $\$ 15,000$ & 93.2 & 0.943 & 82.3 & 98.2 & 22.9 & 8.4 & 5.8 & 62.9 \\
\hline 5. $\$ 10,000$ & 95.6 & 1.061 & 83.5 & 98.3 & 22.7 & 8.6 & 5.8 & 62.8 \\
\hline 6. $\$ 5,000$ & 96.9 & 1.130 & 85.0 & 98.4 & 22.7 & 8.7 & 5.8 & 62.8 \\
\hline 7. $\$ 2,000$ & 97.4 & 1.135 & 85.4 & 98.4 & 22.7 & 8.7 & 5.9 & 62.8 \\
\hline
\end{tabular}

Table 10: Effects of work-dependent asset testing (non-disabled, age 25-64).

\section{Relationship with recent empirical studies}

Recently, several empirical studies have addressed the question of the effect of public health insurance on labor supply using changes in the Medicaid state expansion programs in different states. In this section, we argue that even though these studies reach opposite conclusions, they can be reconciled in light of our findings.

Garthwaite et al. (2014) consider the changes in Tenncare, the state expansion program for childless adults in Tennessee. Tenncare was launched in 1994, but in 2005 due to state budget problems, around 170,000 adults were disenrolled from this program within a period of several months. Garthwaite et al. (2014) find that there was a large increase in employment among disenrolled individuals.

Dague et al. (2013) study the BadgerCare Plus Core Plan, the state Medicaid expansion program for childless adults in Wisconsin. This program was launched in January 2009. However, several months later, the enrollment was frozen because the number of applications significantly exceeded that planned in the program budget. Those people who applied after the enrollment freeze were placed on a waiting list. The authors compare the labor market outcome of those people who entered the program before the freeze with the outcome of people who were placed on the waiting list. They find that public health insurance enrollment led to a sizeable and statistically significant reduction in employment probability.

Finally, Baicker et al. (2014) use the data from the Oregon Health Insurance experiment to evaluate the effect of Medicaid on labor supply. In 2008, Oregon introduced a limited expansion of its Medicaid program through a lottery. Individuals selected by a lottery were given an opportunity to enroll in Medicaid if they met certain eligibility requirements. The authors do not find a significant difference in terms of labor supply between the group who won the lottery and enrolled in Medicaid and the group who did not win the lottery.

An important observation is that neither Tenncare nor BadgerCare Plus had asset testing for its enrollees. In contrast, individuals who won the lottery in Oregon had to 
meet a strict asset limit of $\$ 2,000$ to be able to enroll in Medicaid. ${ }^{46}$ As our results in section 7.1 show, imposing an asset limit of $\$ 2,000$ can almost entirely eliminate moral hazard behavior among Medicaid beneficiaries; thus, the effect of Medicaid on labor supply should be small or not significant. In contrast, when there is no asset testing, the problem of moral hazard among Medicaid beneficiaries can be considerable, i.e., many individuals reduce their labor supply to enroll in Medicaid. In this light, the opposite findings in these empirical studies can be attributed to different asset testing policies for the Medicaid expansion programs in the three states.

\section{Conclusion}

In this paper, we illustrate the important role of asset testing in improving the incentives of means-tested programs in the asymmetric information environment. The eligibility for means-tested programs depends on endogenous labor income, meaning that people who do not work can become eligible even when their productivity is relatively high. We focus on Medicaid, one of the largest means-tested programs in the US, and we show that in the asymmetric information environment, the labor supply distortions caused by Medicaid's income testing are quantitatively important; around $23 \%$ of Medicaid enrollees would choose to work if they could keep public insurance. These distortions result in large welfare losses; if we remove asymmetric information and allow the participation in Medicaid to be based on (unobservable) exogenous productivity, the ex-ante welfare gains would be equivalent to $1.17 \%$ of annual consumption. These gains arise from the improved allocation of limited public resources; public transfers are reallocated from nonworking Medicaid enrollees with relatively high potential earnings to people with truly low productivity. We show that strict uniform asset testing can almost entirely eliminate the labor supply distortions created by Medicaid but at a cost of distorting saving decisions. To achieve an outcome close to the "ideal" full information case (observable productivity), asset limits should be different for workers and non-workers. This happens because imposing strict asset testing on Medicaid beneficiaries who work is redundant and only distorts their saving decisions.

Note that the framework developed in this paper can be used to study other meanstested programs apart from Medicaid. In particular, such programs as Temporary Assistance for Needy Families (TANF), food stamps, and SSI base their eligibility on earnings and thus can also distort labor supply decisions. Our finding that work-dependent asset testing can improve upon the situation with no asset testing or that with uniform asset testing is likely to apply to these programs as well. Our approach can be used to quantify

\footnotetext{
${ }^{46}$ Source: Wooldridge et al. (1996) for Tenncare, Kaiser Commission on Medicaid and the Uninsured (2010) for BadgerCare Plus, and Baicker et al. (2014) for the Oregon lottery.
} 
the effects of asset testing polices in these programs. Our model can also be extended to allow for intensive labor supply adjustments, in which case it can be used to analyze a wider range of programs, for example, Earned Income Tax Credit (EITC), a program that is designed to increase labor supply among low-income people.

We see two important future extensions of our work. First is to understand how Medicaid interacts with other public programs, in particular, disability insurance. More specifically, what is the joint effect of Medicaid and disability insurance on work incentives? The detailed modeling of these two programs is a non-trivial extension, but it will allow for an extensive policy analysis. In particular, it will allow answering the following questions. Does decreasing the size of the moral hazard problem in Medicaid affect the number of applicants falsely claiming disability insurance? How do changes in the screening process of the disability insurance program affect the size of the moral hazard problem in Medicaid? Is it possible to reduce the disincentives of the two programs simultaneously while maintaining the amount of insurance they provide?

Second, we consider it an important extension to understand how the changes introduced by the Affordable Care Act (ACA) will affect the work incentives of Medicaid beneficiaries. This reform, which began to be implemented in 2014, has several provisions that are likely to affect the incentives of the publicly insured. First, the ACA eliminates asset testing of Medicaid beneficiaries. As we show in the paper, this negatively affects work incentives. At the same time, the reform introduces community rating in the individual market and subsidies for people buying individual health insurance. This facilitates access to private health insurance and thus decreases the attractiveness of Medicaid. Our framework can be extended to quantify the importance of these two forces and their net effect on work incentives. 


\section{References}

[1] Attanasio, O., Kitao, S., Violante G., 2011. Financing Medicare: A General Equilibrium Analysis. In Shoven, J.B. (Ed.), Demography and the Economy, University of Chicago Press.

[2] Capatina, E., 2015. "Life-cycle Effects of Health Risk". Journal of Monetary Economics

[3] Albanesi, S., Sleet, C., 2006. Dynamic Optimal Taxation with Private Information. Review of Economic Studies, 73, pp 1-30

[4] Baicker, K., Finkelstein, A., Song, J., Taubman, S., 2014. The Impact of Medicaid on Labor Force Activity and Program Participation: Evidence from the Oregon Health Insurance Experiment. American Economic Review: Papers \& Proceedings, 104(5): pp 322-328.

[5] Benitez-Silva, H., Buchinsky, M., Rust, J., 2006. How Large are the Classification Errors in the Social Security Disability Award Process? Manuscript, SUNY-Stony Brook

[6] Blank, R. M. (1989). The Effect of Medical Need and Medicaid on AFDC Participation. Journal of Human Resources, 24(1), 54-87.

[7] Congressional Budget Office, 2013. "Growth in Means-Tested Programs and Tax Credits for Low-Income Households". February 2013, available online at http://www.cbo.gov/sites/default/files/cbofiles/attachments/43934-MeansTestedPrograms.pdf

[8] Chetty, R., Guren, A., Manoli, D., Weber, A., 2012. Does Indivisible Labor Explain the Difference between Micro and Macro Elasticities? A Meta-Analysis of Extensive Margin Elasticities. NBER Chapters, in: NBER Macroeconomics Annual 2012 (27) $1-56$.

[9] Conesa, J. C., Krueger, D., 2006. On the Optimal Progressivity of the Income Tax Code. Journal of Monetary Economics 53(7), 1425-1450.

[10] Cutler, D., Gruber, J., 1996. Does Public Insurance Crowd Out Private Insurance? Quarterly Journal of Economics 111(2), 391-430.

[11] Cutler, D., Lleras-Muney, A., and Vogl, T. 2011 "Socioeconomic status and health: dimensions and mechanisms". Oxford Handbook of Health Economics

[12] Dague, L., DeLire, T., Leininger, L., 2013. The Effect of Public Insurance Coverage for Childless Adults on Labor Supply. NBER Working Paper 20111.

[13] Dave, D., Decker, S., Kaestner, R., Simon, K., 2013. The Effect of Medicaid Expansions in the Late 1980s and Early 1990s on the Labor Supply of Pregnant Women. NBER Working Paper 19161.

[14] De Nardi, M., French, E., Jones, J., 2010. Why Do the Elderly Save? Journal of Political Economy, 118(1), 39-75. 
[15] Decker, S., 1993. The effect of Medicaid on access to health care and welfare participation. Ph.D. Dissertation. Harvard University.

[16] Decker, S, Selck, F., 2011. The Effect of the Original Introduction of Medicaid on Welfare Participation and Female Labor Supply. Working paper.

[17] Garthwaite C., Gross, T., Notowidigdo, M., 2014. Public Health Insurance, Labor Supply, and Employmnet Lock. The Quarterly Journal of Economics, 129 (2), pp 653-696.

[18] Ellwood, D., Adams, K., 1990. Medicaid mysteries: Transitional benefits, Medicaid coverage, and welfare exits. Health Care Financing Review, 1990 Annual Supplement, 119-131.

[19] Erosa, A., Fuster, L., Kambourov, G. 2011 Towards a micro-founded theory of aggregate labor supply. IMDEA Working Papers N 2011-13

[20] Floden, M., 2008. A Note on the Accuracy of Markov-chain Approximations to Highly Persistent AR(1) Processes. Economic Letters 99(3), 516-520.

[21] French, E., 2005. The Effects of Health, Wealth, and Wages on Labor Supply and Retirement Behavior. Review of Economic Studies, 72(2), pages 395-427.

[22] French, E., Jones, J. 2011. The Effects of Health Insurance and Self-Insurance on Retirement Behavior. Econometrica, 79(3), pages 693-732.

[23] Ganong, P. Liebman, J., 2013. "The Decline, Rebound, and Further Rise in SNAP Enrollment: Disentangling Business Cycle Fluctuations and Policy Changes". NBER Working Paper No. 19363

[24] Golosov, M., Kocherlakota, N., and Tsyvinski, A., 2003. Optimal Indirect and Capital Taxation. Review of Economic Studies, 70(3), pp 569-87

[25] Golosov, M., Tsyvinski, A., 2006. Designing Optimal Disability Insurance: A Case for Asset Testing. Journal of Political Economy, Vol 114(2)

[26] Golosov, M., Tsyvinski, A., Werning, I., 2006. New Dynamic Public Finance: A User's Guide. NBER Macroeconomic Annual

[27] Gruber, J., Madrian, B., 2004. Health Insurance, Labor Supply and Job Mobility: A Critical Review of the Literature. In "Health Policy and the Uninsured", Catherine G. McLaughlin, ed. Washington, DC: Urban Institute Press, pp. 97-178.

[28] Gruber, J., Yelowitz, A., 1999. Public Health Insurance and Private Saving. Journal of Political Economy, 107(6), 1249-74

[29] Hansen, G., Hsu, M., Lee, J., 2014. Health Insurance Reform: The impact of a Medicare Buy-In. Journal of Economic Dynamics and Control, 45, 315-329.

[30] Heathcote, J., Storesletten, K., Violante, G., 2010 The Macroeconomic Implications of Rising Wage Inequality in the United States. Journal of Political Economy, vol. 118(4), pages 681-722. 
[31] Heberlein, M., Brooks, T., Guyer, J., Artiga, S., Stephens, J., 20112. "Performing under Pressure: Annual Findings of a 50-State Survey of Eligibility, Enrollment, Renewal, and Cost-Sharing Policies in Mediciadi and SCHIP, 2011-2012". Kaiser Commission on Medicaid and the Uninsured.

[32] Heckman, J., 1993. What Has Been Learned About Labor Supply in the Past Twenty Years? American Economic Review Papers and Proceedings 83(2), pages 116-121.

[33] Hsu, M., 2013. Health Insurance and Precautionary Saving: a Structural Analysis. Review of Economic Dynamics, 16:3, 511-526

[34] Hubbard, G., Skinner, J., Zeldes, S., 1994. The Importance of Precautionary Motives in Explaining Individual and Aggregate Saving. Carnegie-Rochester Conference Series on Public Policy 40(1), 59-125.

[35] Jeske, K., Kitao, S., 2009. U.S. Tax Policy and Health Insurance Demand: Can a Regressive Policy Improve Welfare? Journal of Monetary Economics, 56(2), 210-221.

[36] Kaiser Commission on Medicaid and the Uninsured, 2010. Expanding Medicaid to Low?Income Childless Adults under Health Reform: Key Lessons from State Experiences. Available at http://kaiserfamilyfoundation.files.wordpress.com/2013/01/8087.pdf

[37] Kaiser Family Foundation, 2004. The Cost of Care for the Uninsured. What Do We Spend, Who Pays, and What Would Full Coverage Add to Medical Spending? Available at http://www.kff.org/uninsured/upload/The-Cost-of-Care-for-theUninsured-What-Do-We-Spend-Who-Pays-and-What-Would-Full-Coverage-Addto-Medical-Spending.pdf

[38] Kaiser Family Foundation, 2009. Employer Health Benefits Survey. Available at http://ehbs.kff.org/2009.html

[39] Kitao, S., 2015. A Life Cycle Model of Unemployment and Disability Insurance. Journal of Monetary Economics.

[40] Klein, K., Schwartz, S, 2008. State Efforts to cover Low-Income Adults Without Children. State Health Policy Monitor, September 2008, National Academy for State Health Policy.

[41] Kleven, K., Kreiner, C, 2005. Labor Supply Behavior and the Design of Tax and Transfer Policy. Danish Journal of Economics 143, pp. 321-358.

[42] Kocherlakota, N., 2005. Zero Expected Wealth Taxes: A Mirrlees Approach to Dynamic Optimal Taxation. Econometrica, 73(5), pp 1587-1621

[43] Kocherlakota, N., 2010. The New Dynamic Public Finance, Princeton, Princeton University Press

[44] Low, H., Pistaferri, L., 2012. Disability Insurance and the Dynamics of the IncentiveInsurance Tradeoff. Mimeo, Stanford University 
[45] Montgomery, E., Navin, J., 2000. Cross-state variation in Medicaid program and female labor supply. Economic Inquiry 38 (3), 402-418.

[46] Moffitt, R. 2002. Economic Effects of Means-Tested Transfers in the U.S. NBER book: Tax Policy and the Economy (Volume 16).

[47] Moffitt, R., Wolfe, B. 1992. The Effect of Mediciad Program on Program Participation and Labor supply. Review of Economics and Statistics, 74(4), 615-626.

[48] Nagi, S. Z., 1969. Disability and Rehabilitation. Columbus, OH: Ohio State University Press.

[49] Nakajima, M., Telyukova, I. 2012. Home Equity in Retirement. Working paper, Federal Reserve Bank of Philladephia.

[50] Pashchenko, S., Porapakkarm, P., 2013. Quantitative Analysis of Health Insurance Reform: Separating Regulation from Redistribution. Review of Economic Dynamics 16, 383-404.

[51] Pashchenko, S., Porapakkarm, P., 2016. Medical Spending in the US: Facts from the Medical Expenditure Panel Survey Datase. Forthcoming, Fiscal Studies.

[52] Pohl, V., 2011. Medicaid and the Labor Supply of Single Mothers: Implications for Health Care Reform. Mimeo, University of Georgia

[53] Saez, E., 2002. Optimal Income Transfer Programs: Intensive Versus Extensive Labor Supply Responses. Quarterly Journal of Economics 117(3), 1039-1073.

[54] Storesletten, K., Telmer, C., Yaron, Y., 2004. Consumption and Risk Sharing Over the Life Cycle. Journal of Monetary Economics 51(3), 609-633.

[55] Strumpf, E., 2011. Medicaid's Effect on Single Women's Labor Supply: Evidence From the Introduction of Medicaid. Journal of Health Economics, 30(3):531-548.

[56] Sullivan, J., 2005 "Welfare Reform, Saving, and Vehicle Ownership: Do Asset Limits and Vehicle Exemptions Matter?", Journal of Human Resources

[57] Winkler, A. E. (1991). The Incentive Effects of Medicaid on Women's Labor Supply. Journal of Human Resources, 26(2), 308-337.

[58] Wooldridge, J., Ku, L., Coughlin, T., Dubay, L., Ellwood, M., Rajan, S., Hoag, S., 1996. Implementing State Health Care Reform: What Have We Learned from the First Year? The First Annual Report of the Evaluation of Health Reform in Five States. Mathematica Policy Research Report available at http://mathematicampr.com/publications/pdfs/health/implementstatehealth.pdf.

[59] Yelowitz, A., 1995. The Medicaid Notch, Labor Supply, and Welfare Participation: Evidence from Eligibility Expansions. The Quarterly Journal of Economics, 110(4):909-939.

[60] Young, E., 2010. Solving the Incomplete Markets Model with Aggregate Uncertainty Using the Krusell-Smith Algorithm and Non-Stochastic Simulations. Journal of Economic Dynamics and Control, 34(1), 36-41. 
[61] Zayatz. T., 2011. Social Security Disability Insurance Program Worker Experience, Actuarial Study 122, Social Security Administration Pub No. 11-11543 


\section{Appendix}

\section{A Summary of the parametrization of the baseline model}

\begin{tabular}{|c|c|c|c|}
\hline Parameter name & Notation & Value & Source \\
\hline $\begin{array}{l}\text { Parameters set outside the model } \\
\text { Consumption share } \\
\text { Cobb-Douglas parameter } \\
\text { Depreciation rate } \\
\text { Population growth } \\
\text { Labor supply } \\
\text { Tax function parameters } \\
\text { Disability payment } \\
\text { Medicare premium } \\
\text { Asset limit for Medically Needy } \\
\text { Employer contribution } \\
\text { Labor productivity } \\
\text { - Persistence parameter } \\
\text { - Variance of innovations } \\
\text { - Temporary shock } \\
\text { - Fixed effect }\end{array}$ & $\begin{array}{c}\varkappa \\
\alpha \\
\delta \\
\eta \\
\bar{l} \\
a_{0} \\
a_{1} \\
D I \\
p^{m e d} \\
k^{M N} \\
\psi\end{array}$ & $\begin{array}{c}0.6 \\
0.33 \\
0.085 \\
0.7 \% \\
0.4 \\
0.258 \\
0.768 \\
\$ 4,920 \\
\$ 1,055 \\
\$ 2,000 \\
80.0 \%\end{array}$ & $\begin{array}{l}\text { French }(2005) \\
\text { capital share in output } \\
\text { investment-GDP ratio } \\
\% \text { people older than } 65 \\
\text { Gouveia and Strauss }(1994) \\
\text { average Social Security payments among the disabled }(25-61) \\
\text { total premiums }=2.11 \% \text { of } Y \\
\text { data }\end{array}$ \\
\hline $\begin{array}{l}\text { Parameters used to match some target } \\
\text { Discount factor } \\
\text { Risk aversion } \\
\text { Fixed costs of work } \\
\text { Consumption floor } \\
\text { Tax function parameter } \\
\text { Proportional tax } \\
\text { Proportional load in ESHI/ind ins } \\
\text { Fixed loads in ind insurance } \\
\quad \text { - healthy } \\
\text { - unhealthy } \\
\text { Medicaid } \\
\quad \text { - Income test } \\
\text { - Categorial asset test }\end{array}$ & $\begin{array}{c}\beta \\
\sigma \\
\phi_{w} \\
\underline{c} \\
a_{2} \\
\tau_{y} \\
\gamma \\
\varphi^{h}\end{array}$ & $\begin{array}{c}0.9965 \\
2.50 \\
0.28 \\
\$ 1,540 \\
0.616 \\
6.66 \% \\
1.071 \\
\\
\$ 101 \\
\$ 2,100 \\
\\
0.705 F P L \\
\$ 26,000\end{array}$ & $\begin{array}{l}\frac{K}{Y}=2.7 \\
\text { age-profile of individually insured } \\
\text { employment profiles (healthy) } \\
\% \text { employment among Medicaid enrolles } \\
\text { balanced government budget } \\
\text { composition of tax revenue } \\
\% \text { individually insured profile } \\
\% \text { individually insured profile (healthy) } \\
\% \text { individually insured profile (unhealthy) } \\
\% \text { publicly insured } \\
\% \text { Medicaid enrollees with assets below } \$ 10,000\end{array}$ \\
\hline
\end{tabular}

Table 11: Parameters in baseline model 


\section{B Estimation of survival probabilities}

To construct the survival probabilities by health, we follow Attanasio et al. (2011). We use the HRS data to estimate the survival probability as a function of a cubic polynomial of age and gender, using a probit model for each health status. Then, we compute the survival premium - the difference between the estimated survival probabilities of healthy and unhealthy males for each age. From the Social Security Administration life table, we know the average survival probability of males. From the MEPS, we can construct the fraction of people in the two health categories for each age. Using this information, we can recover the survival probabilities of healthy and unhealthy people for each age. Figure (10) plots the survival probability by health status.

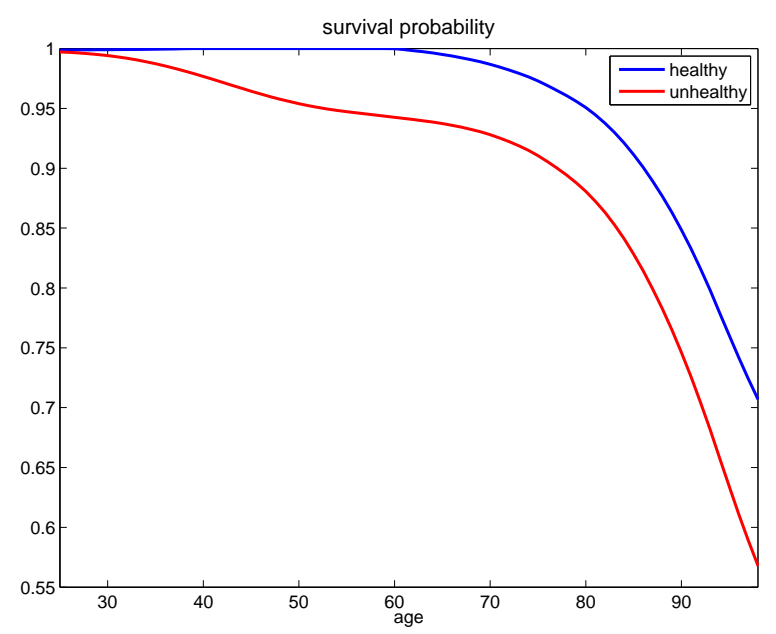

Figure 10: Survival probability $\left(\zeta_{t}\right)$

\section{Medical expenses and insurance coverage}

To calibrate medical expenses, we separate our sample into 12 age groups (20-24, 25$29,30-34, \ldots, 75+)$. We assign the age of each group to the mid-point of the corresponding age interval. For example, 22 for 20-24, 27 for 25-29, 32 for 30-34, etc. For each year, we divide medical expenditures into 3 bins corresponding to the bottom 50th, 50-95th, and top 5th percentiles for each health status and age group. To obtain a value of medical expenses in each bin, we run a regression of medical expenses on a set of age group and year dummies. The coefficients on age dummies in this regression are the average medical expenses for the corresponding age in a particular bin. Then, we fit our estimated coefficients with a quadratic function of age. The resulting numbers are multiplied by 1.60 for people younger than 65 years old and by 1.90 for people who are 65 or older to make medical spending in our model consistent with the aggregate medical spending 
in NHEA as explained in Section 4.6. Figure (11) shows the medical cost for each grid separately for healthy and unhealthy individuals. Table 12 reports the medical shock process transition matrices for people younger than 65 years old and for people who are 65 or older.
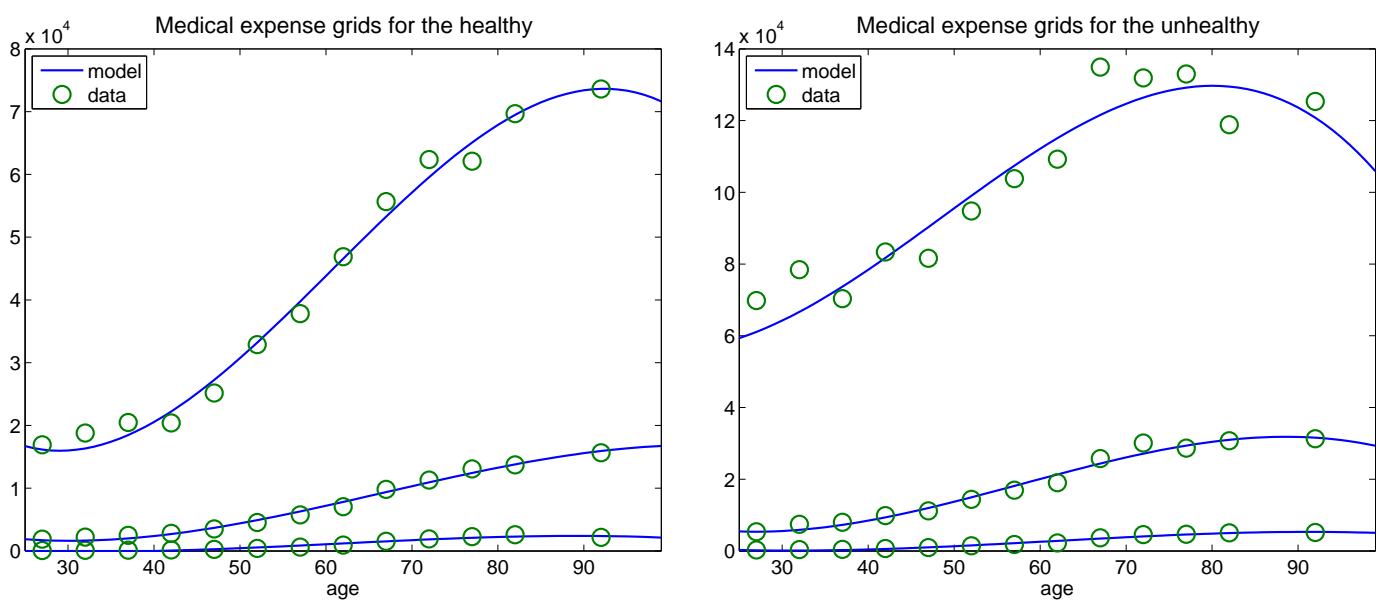

Figure 11: Medical expense grids by health status, $x_{t}^{h}$

\begin{tabular}{cccc}
\hline & $x_{t}(1)$ & $x_{t}(2)$ & $x_{t}(3)$ \\
\hline$x_{t-1}(1)$ & 0.756 & 0.227 & 0.017 \\
$x_{t-1}(2)$ & 0.359 & 0.591 & 0.050 \\
$x_{t-1}(3)$ & 0.221 & 0.616 & 0.163 \\
\hline
\end{tabular}

\begin{tabular}{llll}
\hline & $x_{t}(1)$ & $x_{t}(2)$ & $x_{t}(3)$ \\
\hline$x_{t-1}(1)$ & 0.693 & 0.280 & 0.027 \\
$x_{t-1}(2)$ & 0.350 & 0.578 & 0.072 \\
$x_{t-1}(3)$ & 0.242 & 0.597 & 0.161 \\
\hline
\end{tabular}

Table 12: Transition matrix of medical expenses. Left panel: for individuals younger than 65. Right panel: for individuals who are 65 or older.

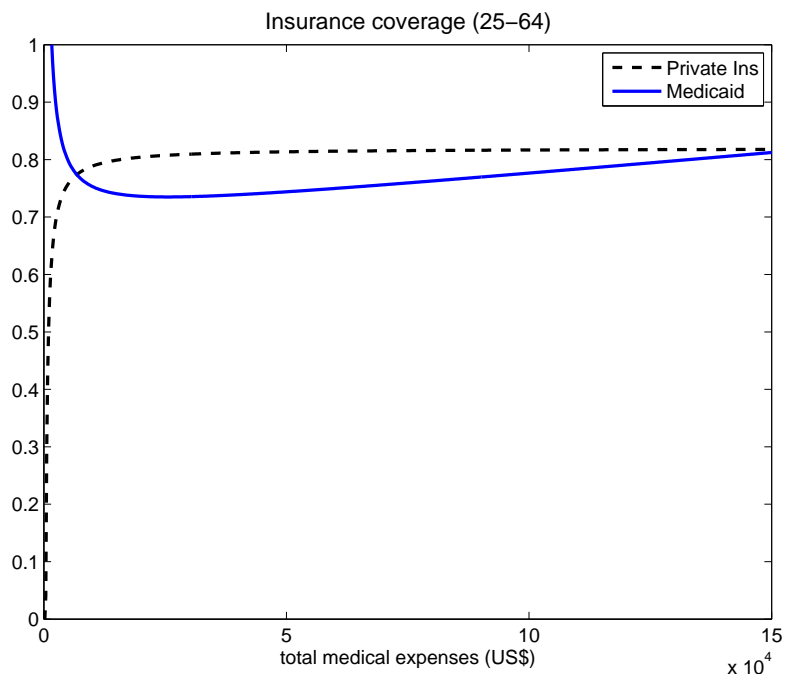

Figure 12: Fraction of medical costs covered by private insurance and Medicaid, $q\left(x_{t}^{h}, i_{t}\right)$ 
To determine the fraction of medical expenses covered by private insurance and Medicaid $q\left(x_{t}, i_{t}\right)$, we do the following. For working-age households, we estimate medical expenditures paid by private insurers (variable TOTPRV) and Medicaid (variable TOTMCD) as a function of total medical expenditures and year dummy variables. We use a linear function of total medical expenditure for private insurance and a quadratic function for Medicaid. ${ }^{47}$ Then, we convert our estimates into the fraction of expenditures covered by insurers. Figure (12) plots the fraction of medical expenses covered by private insurance and Medicaid.

\section{Economy with observable productivity when wel- fare budget is not fixed}

In this section, we reevaluate the welfare effects of linking Medicaid eligibility to exogenous productivity as in Section 6.2 (Eq. 30) but when total spending on welfare programs (Medicaid and the consumption floor) is not held constant. Unlike in Section 6.2 , we do not adjust the income eligibility threshold to keep the welfare budget unchanged but only adjust $\tau_{y}$ to balance the government budget. Tables 13 and 14 report the results from this experiment.

As before, there is a welfare gain from removing asymmetric information, but the size of the gain is significantly smaller: $0.18 \%$ of annual consumption compared with $1.17 \%$ in Section 6.2. This happens because the size of the public transfers through Medicaid decreases. In the experiment in Section 6.2, the freed-up budget from disenrolled Medicaid beneficiaries with relatively high productivity is used to enroll more low-income people. Now, this budget is proportionately distributed to everyone through lower taxes. As a result, the income tax $\tau_{y}$ decreases from $6.66 \%$ to $6.30 \%$, but the Medicaid program shrinks; its coverage goes down from $6.5 \%$ (baseline) to $5.2 \%$.

\section{E Removing asset testing for workers}

In Section 7.2, we show that tight asset testing for non-workers can almost entirely eliminate moral hazard behavior among Medicaid beneficiaries. In this section, we consider the effects of the complete elimination of asset testing for workers while maintaining the strict asset testing $(\$ 2,000)$ for non-workers. Row 3 of Table 15 reports the results of this experiment. For comparison, we also report in Row 2 the results for an economy

\footnotetext{
${ }^{47}$ For both regressions, $R^{2}$ is 0.88 .
} 


\begin{tabular}{lcc}
\hline \hline & Baseline & $\begin{array}{c}\text { Observable } \\
\text { productivity }\end{array}$ \\
\hline Income test: $y^{\text {cat }}, y^{M N}(\% \mathrm{FPL})$ & $70.5 \%$ & $70.5 \%$ \\
Income tax: $\tau_{y}$ & $6.66 \%$ & $6.30 \%$ \\
& & \\
Employment rate (non-disabled, $\mathbf{2 5 - 6 4 ) ( \% )}$ & \\
- all & 93.9 & 95.4 \\
- healthy & 97.7 & 98.1 \\
- unhealthy & 76.9 & 81.5 \\
\% & & \\
$\% \Delta$ aggregate labor productivity & - & 0.36 \\
$\% \Delta$ aggregate capital & - & 1.24 \\
Ex-ante consumption equivalent $(\%)$ & - & 0.65 \\
\hline \hline
\end{tabular}

Table 13: Effects of removing Medicaid distortions on the labor supply (fixed income test limit)

\begin{tabular}{lccccccccc}
\hline \hline & \multicolumn{4}{c}{ Baseline } & & \multicolumn{3}{c}{ observable productivity } \\
\cline { 2 - 4 } & ESHI & individual & uninsured & public & & ESHI & individual & uninsured & public \\
\hline all & 63.5 & 5.6 & 24.3 & 6.5 & & 63.6 & 5.6 & 25.6 & 5.2 \\
healthy & 67.1 & 6.2 & 23.0 & 3.7 & & 67.2 & 6.2 & 23.4 & 3.3 \\
unhealthy & 47.3 & 3.1 & 30.2 & 19.4 & & 47.5 & 3.1 & 35.7 & 13.7 \\
\hline \hline
\end{tabular}

Table 14: Change in insurance coverage (fixed income test limit)

where productivity is observable and there is no asset testing. In both experiments, we fix the total budget of the welfare programs as in the baseline economy by adjusting the income test limit.

Compared with the results in Table 10, the welfare gains are higher. This is because asset testing of working beneficiaries is unnecessary (since there is no moral hazard) and it only creates saving distortions. Table 15 also shows that removing asset testing for workers can achieve welfare gains close to the economy with observable productivity and no asset testing (1.28\% vs $1.41 \%)$.

\begin{tabular}{|c|c|c|c|}
\hline Experiment & $\begin{array}{l}\% \text { non-worker } \Rightarrow \text { worker } \\
\text { if not losing eligibility }\end{array}$ & $\begin{array}{c}\text { Income test } \\
(\% \mathrm{FPL})\end{array}$ & $\begin{array}{c}\text { Ex-ante CEV } \\
(\%)\end{array}$ \\
\hline 1. Baseline & 22.9 & 70.5 & - \\
\hline $\begin{array}{l}\text { 2. Obs productivity, no asset } \\
\text { test }\end{array}$ & - & 93.2 & 1.414 \\
\hline $\begin{array}{l}\text { 3. Asset test }(\$ 2,000) \text { only for } \\
\text { non-workers }\end{array}$ & 1.36 & 93.2 & 1.276 \\
\hline
\end{tabular}

Table 15: Welfare effects of the complete removal of asset testing when productivity is observable (Row 2 ) and the removal of asset testing for workers when productivity is unobservable (Row 3). 


\section{F Earnings-dependent asset testing with intensive margin of labor supply}

In this paper, we assume that individuals adjust their labor supply only along the extensive margin. We show that the distortions of Medicaid can be substantially reduced if Medicaid eligibility includes asset testing that imposes different asset limits on workers and non-workers. In this section, we discuss how this policy would look like if individuals could also adjust their labor supply along the intensive margin.

When individuals can choose how much to work, Medicaid can distort not only participation decisions but also decisions about hours worked. This happens if it is impossible to infer productivity from observing the labor income and hours of working individuals. ${ }^{48}$ In this case, the asset limits can be linked to labor income as follows: the lower the labor income, the tighter the asset test. The intuition here is the same as in the case of our baseline model. When only extensive margin adjustment is possible, highly productive individuals can pretend to be low productive by not working. If intensive margin can also be adjusted, highly productive individuals can decrease their working hours, which results in low labor income. As before, the strategy of mimicking low productivity is only attractive for individuals who have enough assets to substitute forgone labor income when decreasing their labor supply. Thus, tighter asset limits on those with low labor income can discourage individuals with high productivity from enrolling into Medicaid. ${ }^{49}$

\section{G Computational algorithm}

In our computation, we discretize all continuous state variables. Since the value function and policy functions are non-linear along the dimension of $k_{t}$ when $k_{t}$ is close to zero, we use a much finer grid for small values of $k_{t}$. Given the parameters of the model, we solve for the steady state equilibrium of the baseline model as follows.

1. Guess an initial interest rate $r$, premium in the group insurance market $p$, the amount the firm offering ESHI subtracts from the wage of their workers $c_{E}$, tax parameter $a_{2}$, and bequest Beq. ${ }^{50}$

\footnotetext{
${ }^{48}$ This is the common assumption in the NDPF literature. It can happen either because hours are observed imprecisely or because individuals can also adjust their efforts.

${ }^{49}$ Note that earnings-dependent asset limits are analogous to earnings-dependent wealth taxation, as discussed in the NDPF literature. Albanesi and Sleet (2005) find that optimal tax on wealth is a nonlinear function of labor income that increases steeply when labor income is close to zero. Therefore, it is possible that in our case, asset limits can be a complicated non-linear function of labor income.

${ }^{50}$ In general, insurance markets where firms are not allowed to risk-adjust premiums, as in the group market, can have multiple equilibriums. However, because the major part of the premium is contributed by the employer, people are less sensitive to the price of insurance; thus, the multiplicity of equilibriums becomes less of an issue. In particular, our equilibrium price tends to be invariant to the initial guess.
} 
2. Solve for the households' decision rules using backward induction. We evaluate the value function for points outside the state space grid using a Piecewise Cubic Hermite Interpolating Polynomial (PCHIP).

3. Given policy functions, simulate the households' distribution using a non-stochastic method as in Young (2010).

4. Using the distribution of households and policy functions, check whether market clearing conditions and zero profit conditions for insurance firms hold, and government budget balances. If not, update $r, p, c_{E}, a_{2}$, and $B e q$, and repeat Steps 1-3. 